\title{
Effects of Different Particle Size Distributions on Aluminum Particle-Air Detonation
}

\author{
Z. J. Zhang* \\ University of Chinese Academy of Sciences, 100049 Beijing, People's Republic of China \\ C. Y. Wen \\ The Hong Kong Polytechnic University, Kowloon, Hong Kong, People's Republic of China \\ and \\ Y. F. Liu, D. L. Zhang,,$\underline{\S}$ and Z. L. Jiang』 \\ Chinese Academy of Sciences, 100190 Beijing, People's Republic of China
}

https://doi.org/10.2514/1.J058237

\begin{abstract}
Due to the involvement of powder materials in dust explosion hazards and detonation experiments, it is imperative to analyze the heterogeneous detonation in a polydisperse suspension with a continuous particle size distribution. Notably, most current studies are limited to monodisperse suspensions with only one particle size. In this study, the rich $2 \mu \mathrm{m}$ aluminum particle-air detonation with two particle size distributions (namely, the monodisperse and the polydisperse with log-normal particle size distribution) is numerically studied by using the Eulerian-Lagrangian method along with a new hybrid aluminum combustion model. Significant discrepancies of the one-dimensional detonation front structures are observed between the monodisperse detonation and the polydisperse counterpart. And, the physical mechanisms of these discrepancies have been revealed by decoupling the gas-particles interactions with the one-dimensional flow theory. It is mainly caused by the different timings of the particle phase transition processes and the consequently different heat transfer characteristics, which are the effects of multiple timescales and length scales in the polydisperse detonation. Furthermore, owing to the wider reaction zones of polydisperse detonations than that of the monodisperse counterpart, discrepancies of two-dimensional detonation cell sizes are observed as well. This study reveals the great importance of considering particle size distribution in heterogeneous detonation simulations.
\end{abstract}

\section{Nomenclature}

$C_{D} \quad=$ drag coefficient

$C_{\mathrm{O}_{2}}=$ mole concentration of oxygen, $\mathrm{mol} / \mathrm{m}^{3}$

$C_{p}=$ dust concentration, $\mathrm{kg} / \mathrm{m}^{3}$

$C_{\text {total }}=$ total mole concentration of gas, $\mathrm{mol} / \mathrm{m}^{3}$

$c_{p}=$ gas specific heat at constant pressure, $\mathrm{J} /(\mathrm{kg} \cdot \mathrm{K})$

$D=$ detonation velocity, $\mathrm{m} / \mathrm{s}$

$d t \quad=$ global time step, $\mathrm{s}$

$d_{\mathrm{nM}}=$ number median diameter, $\mathrm{m}$

$d_{p}=$ particle diameter, $\mathrm{m}$

$\bar{d} \quad=\quad$ volume-average particle diameter, $\mathrm{m}$

$\bar{d}_{m} \quad=$ mass-weighted-average particle diameter, $\mathrm{m}$

$d t^{\prime}=$ subtime step, $\mathrm{s}$

$E=$ total energy density of gas, $\mathrm{J} / \mathrm{m}^{3}$

$E_{a}=$ activation energy, $\mathrm{J} / \mathrm{mol}$

$E_{p}=$ total energy of particle, $\mathrm{J}$

$e_{p}=$ specific internal energy of particle, $\mathrm{J} / \mathrm{kg}$

$f=$ force acted on gas per unit volume, $\mathrm{N} / \mathrm{m}^{3}$

Received 22 December 2018; revision received 12 November 2019; accepted for publication 20 February 2020; published online 27 May 2020. Copyright $\odot 2020$ by the American Institute of Aeronautics and Astronautics, Inc. All rights reserved. All requests for copying and permission to reprint should be submitted to CCC at www.copyright.com; employ the eISSN 1533-385X to initiate your request. See also AIAA Rights and Permissions www.aiaa.org/randp

*Ph.D. Candidate, School of Engineering Sciences; also Institute of Mechanics, Chinese Academy of Sciences, 100190 Beijing, People's Republic of China.

${ }^{\dagger}$ Professor, Department of Mechanical Engineering and Interdisciplinary Division of Aeronautical and Aviation Engineering. Associate Fellow AIAA.

${ }^{\ddagger}$ Associate Professor, Institute of Mechanics; also School of Engineering Sciences, University of Chinese Academy of Sciences, 100049 Beijing, People's Republic of China; liuyunfeng @imech.ac.cn (Corresponding Author).

${ }^{\S}$ Professor, Institute of Mechanics.

'Professor, Institute of Mechanics; also School of Engineering Sciences, University of Chinese Academy of Sciences, 100049 Beijing, People's Republic of China. Associate Fellow AIAA. $f_{n}=$ number frequency distribution function, $1 / \mathrm{m}$

$f_{x}=x$ component of particle drag, $\mathrm{N}$

$f_{y}=y$ component of particle drag, $\mathrm{N}$

$h=$ specific enthalpy of gas, $\mathrm{J} / \mathrm{kg}$

$h_{i} \quad=\quad$ specific enthalpy of gaseous species, $\mathrm{J} / \mathrm{kg}$

$I_{p} \quad=\quad$ rate of mass consumption or production due to combustion, $\mathrm{kg} / \mathrm{s}$

$K=$ diffusion reaction coefficient, $\mathrm{s} / \mathrm{m}^{2}$

$=$ coefficient in calculation of $Q_{p}, \mathrm{~J} /(\mathrm{s} \cdot \mathrm{K})$

$k_{d}=$ rate coefficient of diffusion reaction $\mathrm{kg} \cdot \mathrm{m} /(\mathrm{mol} \cdot \mathrm{s})$

$k_{0}=$ kinetic reaction coefficient, $\mathrm{kg} \cdot \mathrm{m} /(\mathrm{mol} \cdot \mathrm{s})$

$k_{s}=$ rate coefficient of kinetic reaction, $\mathrm{kg} \cdot \mathrm{m} /(\mathrm{mol} \cdot \mathrm{s})$

$M \quad=\quad$ Mach number in front-fitted coordinate system

$m_{p} \quad=\quad$ particle mass, $\mathrm{kg}$

$N=$ number of subtime steps

$N_{p}=$ number of particles in one computational mesh

$N u_{p}=$ particle Nusselt number

$\mathrm{Pr}=$ Prandtl number

$p \quad=\quad$ gas pressure, $\mathrm{Pa}$

$Q_{p} \quad=\quad$ summation of particle convection heat transfer, $\mathrm{J} / \mathrm{s}$

$\dot{Q}_{q}=$ rate of convection heat transferred to gas per unit volume, $\mathrm{J} /\left(\mathrm{m}^{3} \cdot \mathrm{s}\right)$

$\dot{Q}_{r} \quad=\quad$ rate of reaction heat released to gas per unit volume, $\mathrm{J} /\left(\mathrm{m}^{3} \cdot \mathrm{s}\right)$

$q_{p} \quad=\quad$ particle convection heat transfer, $\mathrm{J} / \mathrm{s}$

$R e_{p}=$ particle Reynolds number

$R_{0}=$ universal gas constant, $\mathrm{J} /(\mathrm{mol} \cdot \mathrm{K})$

$T=$ gas temperature, $\mathrm{K}$

$T_{p}=$ particle temperature, $\mathrm{K}$

$T_{s} \quad=\quad$ particle surface temperature, $\mathrm{K}$

$\bar{T}_{p} \quad=$ average particle temperature, $\mathrm{K}$

$t=$ time, $\mathrm{s}$

$U=$ gas velocity in front-fitted coordinate system, $\mathrm{m} / \mathrm{s}$

$u=x$ component of gas velocity, $\mathrm{m} / \mathrm{s}$

$u_{p}=x$ component of particle velocity, $\mathrm{m} / \mathrm{s}$

$V=$ magnitude of gas velocity, $\mathrm{m} / \mathrm{s}$

$V_{p} \quad=$ magnitude of particle velocity, $\mathrm{m} / \mathrm{s}$ 
$v=y$ component of gas velocity, $\mathrm{m} / \mathrm{s}$

$v_{p}=y$ component of particle velocity, $\mathrm{m} / \mathrm{s}$

$W \quad=$ molecular weight, $\mathrm{g} / \mathrm{mol}$

$x=x$ coordinate of gas, $\mathrm{m}$

$x_{p}=x$ coordinate of particle, $\mathrm{m}$

$y=y$ coordinate of gas, $\mathrm{m}$

$y_{p}=y$ coordinate of particle, $\mathrm{m}$

$\gamma=$ gas specific heat ratio

$\Delta h=$ interparticle distance, $\mathrm{m}$

$\lambda=$ gas heat conduction coefficient, $\mathrm{W} /(\mathrm{m} \cdot \mathrm{K})$

detonation cell size, $m$

gas viscosity coefficient, $\mathrm{Pa} \cdot \mathrm{s}$

stoichiometric coefficient

gas density, $\mathrm{kg} / \mathrm{m}^{3}$

$\begin{array}{ll}\rho_{i} & =\text { gas species density, } \mathrm{kg} / \mathrm{m}^{3} \\ \rho_{j} & =\text { solid density, } \mathrm{kg} / \mathrm{m}^{3}\end{array}$

$\begin{array}{ll}\rho_{i} & =\text { gas species density, } \mathrm{kg} / \mathrm{m} \\ \rho_{j} & =\text { solid density, } \mathrm{kg} / \mathrm{m}^{3}\end{array}$

$\dot{\rho}=$ rate of mass transferred to gas per unit volume, $\mathrm{kg} /\left(\mathrm{m}^{3} \cdot \mathrm{s}\right)$

$\sigma_{0} \quad=\quad$ standard deviation, $1 / \mathrm{m}$

Subscripts

$\mathrm{CJ}=$

$i=$

$k \quad=$

$m \quad=$

$\max =$

$p \quad=$

$q \quad=$

$r \quad=$

$s \quad=$ index for particle surface

$0=$ initial state

\section{Introduction}

$\mathbf{T}$ HE study of detonation processes in heterogeneous mixtures is in high demand, mainly due to issues such as dust explosion hazards and fire safety in factories producing and using powdered materials [1]. Among different types of powders, aluminum (Al) powder, which is a byproduct of the processing process of various $\mathrm{Al}$ products, is drawing considerable attention [2]. Unlike gaseous detonation, there exists great difficulties in Al-gas detonation experiments; and only limited experiment results have been reported. The large characteristic length scale and the extremely high initiation energy in Al-gas detonation experiments make the numerical simulations in heterogeneous detonation studies extremely important [3-5].

With the progress in modeling of $\mathrm{Al}$ combustion and in multiphase flows [6-8], many results of heterogeneous detonation in Al-gas suspensions have been obtained by numerical simulations. Papalexandris $[9,10]$ examined the structure and stability of one-dimensional (1-D) and two-dimensional (2-D) detonations in mixtures of gases and solid particles, and he found that the mass, momentum, and energy transfers between the two phases result in detonation structures that are substantially different from those observed in the purely gaseous detonations. Numerical simulations of both Al-oxygen and Al-air detonations performed by Fedorov and Khmel' [11] and Briand et al. [12] indicate that many characteristic lengths in Al-gas detonation, such as the induction length and the detonation cell size, have different exponential relationships with particle diameter. Another quantitative relationship between the critical initiation energy and the detonation cell size was revealed by Veyssiere et al. [13]. Using the hybrid combustion model proposed by Zhang and Gerrard [8], Teng and Jiang $[14,15]$ evaluated and discussed the impacts of the specific heat of particles and different product phases.

Notably, the Al suspensions considered in most previous Al-gas detonation simulations are monodisperse, which consists of only one particle size. Very few studies used bidisperse Al suspensions consisting of particles of two diameters [16,17]. No simulation result of heterogeneous detonation dealing with polydisperse Al suspensions with continuous particle size distributions was found in the literature. Nevertheless, as it is widely known, Al powders involved in real suspensions are characterized by a specific continuous particle size distribution, with a relatively wide range of particle diameters. Since many characteristics of Al-gas detonation are significantly influenced by the particle size (including initiation energy, deflagration-to-detonation transition distance, burning time, length of reaction zone, cell size, etc. $[5,11,12])$, it is important to systematically study the features of polydisperse Al-gas detonation, the differences with monodisperse detonation, and the effects of multiple time- and length scales in a continuous particle size distribution. Besides, the accuracy of a monodisperse model for applications in the real world needs to be carefully examined, which leads to the question of whether an equivalent particle diameter could represent the polydisperse $\mathrm{Al}$ suspension for modeling in numerical simulations.

To take the particle size distributions in real $\mathrm{Al}$ suspensions into account, an Eulerian-Lagrangian method is chosen to solve the polydisperse Al-gas two-phase detonation problems in this study. The Eulerian-Lagrangian method is widely used in the multiphase lowspeed incompressible flows $[18,19]$ but rarely used in the high-speed reactive flows. This method tracks every Lagrangian particle of condensed phase by Newton's laws of motion, and it is more capable and realistic in dealing with multiphase suspension flows with particle size distributions. Notably, this method also has its own weakness, which is the high computational cost due to the very large number of particles needed to resolve a typical multiphase suspension flow. However, benefitting from the rapid development of computer technologies, high-performance computer clusters are readily accessible and parallel computing techniques can be used to accelerate the computations, making the Eulerian-Lagrangian simulations of Al-gas detonations possible. Another under-resolved Eulerian-Lagrangian method (also known as the discrete parcel method) should be noticed, which can be used to reduce the computational cost. As this method tracks each particle parcel that contains several particles with the same dynamics and thermal properties [20], it may not be able to capture the full detonation features with different particle size distributions.

Accordingly, in this study, both 1-D and 2-D polydisperse Al-air detonations with a log-normal particle size distribution are studied numerically by the Eulerian-Lagrangian method, and the results are compared with those of monodisperse Al-air suspensions. The effects of multiple timescales and length scales in polydisperse Al-air detonation are discussed in detail.

\section{Physical Models and Numerical Methods}

\section{A. Governing Equations}

Consider the heterogeneous detonation in a mixture consisting of small spherical Al particles suspended in air and assume that the mixture is diluted enough to neglect the volume fraction of Al particles and particle-particle collisions. In the highly transient two-phase flow with strong shock waves, the gas and particles are treated as in thermal and mechanical nonequilibrium, which means that the momentum exchange and heat transfer between the gas and particles are under consideration. Following the approaches in Refs. $[8,14]$ to deal with the condensed combustion product of aluminum oxide $\left(\mathrm{Al}_{2} \mathrm{O}_{3}\right)$, the oxidation of $\mathrm{Al}$ is assumed take place on the surface of the particle and the product $\mathrm{Al}_{2} \mathrm{O}_{3}$ exists in a form of condensed state along with the condensed $\mathrm{Al}$ rather than in the gas phase. Thus, a particle when burning is assumed to be composed of two parts, which are $\mathrm{Al}$ and $\mathrm{Al}_{2} \mathrm{O}_{3}$, and which agree with the experimental observations in Ref. [21].

In the Eulerian-Lagrangian method, the motion of every particle is tracked by Newton's laws of motion. The motion of gas is still described by the Euler equations, and the gas-particles interactions (including mass, momentum, and energy transfers) are presented as source terms. In this study, the air is modeled by two gaseous species, namely, oxygen $\left(\mathrm{O}_{2}\right)$ and nitrogen $\left(\mathrm{N}_{2}\right)$, with their initial volume fractions of 21 and $79 \%$, respectively. Then, the 2-D governing equations of gas phase can be written as follows:

$$
\frac{\partial \boldsymbol{U}}{\partial t}+\frac{\partial \boldsymbol{F}}{\partial x}+\frac{\partial \boldsymbol{G}}{\partial y}=\boldsymbol{S}
$$


where $\boldsymbol{U}$ is the vector of conserved variables, $\boldsymbol{F}$ and $\boldsymbol{G}$ are the conservation flux vectors in the $x$ and $y$ directions, and $\boldsymbol{S}$ is the vector of source terms:

$$
\boldsymbol{U}=\left[\begin{array}{c}
\rho_{\mathrm{O}_{2}} \\
\rho_{\mathrm{N}_{2}} \\
\rho u \\
\rho v \\
E
\end{array}\right], \quad \boldsymbol{F}=\left[\begin{array}{c}
\rho_{\mathrm{O}_{2}} u \\
\rho_{\mathrm{N}_{2}} u \\
\rho u^{2}+p \\
\rho u v \\
(E+p) u
\end{array}\right], \quad \boldsymbol{G}=\left[\begin{array}{c}
\rho_{\mathrm{O}_{2}} v \\
\rho_{\mathrm{N}_{2}} v \\
\rho u v \\
\rho v^{2}+p \\
(E+p) v
\end{array}\right]
$$

and

$$
\boldsymbol{S}=\left[\begin{array}{c}
-\sum_{1}^{N p} \frac{I_{p k, \mathrm{O}_{2}}}{d V} \\
0 \\
-\sum_{1}^{N p} \frac{f_{x k}+u_{p k}\left(I_{p k, \mathrm{Al}_{2} \mathrm{O}_{3}}-I_{p k, \mathrm{Al}}\right)}{d V} \\
-\sum_{1}^{N p} \frac{f_{y k}+v_{p k}\left(I_{p k, \mathrm{Al}_{2} \mathrm{O}_{3}}-I_{p k, \mathrm{Al}}\right)}{d V} \\
-\sum_{1}^{N p} \frac{q_{p k}+u_{p k} f_{x k}+v_{p k} f_{y k}+\frac{1}{2}\left(u_{p k}^{2}+v_{p k}^{2}\right)\left(I_{p k, \mathrm{Al}_{2} \mathrm{O}_{3}}-I_{p k, \mathrm{Al}}\right)+\left(e_{p k, \mathrm{Al}_{2} \mathrm{O}_{3}} I_{p k, \mathrm{Al}_{2} \mathrm{O}_{3}}-e_{p k, \mathrm{Al}} I_{p k, \mathrm{Al}}\right)}{d V}
\end{array}\right]
$$

where the subscript $k$ refers to the $k$ th $\left(k\right.$ from one to $N_{p}$ ) particle, $N_{p}$ is the number of particles in one computational mesh, and $d V$ is the volume of the computational mesh.

In the preceding equations, the total density $\rho$ and total energy $E$ are calculated by

$$
\rho=\sum \rho_{i}, \quad E=\rho h-p+\frac{1}{2} \rho\left(u^{2}+v^{2}\right)
$$

where the subscript $i$ refers to each gaseous species; that is, $i=\mathrm{O}_{2}$ and $\mathrm{N}_{2}$ in this study. The specific enthalpy $h$ in Eq. (4) can be calculated by

$$
h=\sum \frac{\rho_{i}}{\rho} h_{i}
$$

with the specific enthalpy of each individual species $h_{i}$ obtained from the nine-coefficient NASA polynomial representation [22]. By assuming each individual species as a perfect gas, the equation of state of the gas mixture is

$$
p=\sum \rho_{i} \frac{R_{0}}{W_{i}} T
$$

The specific internal energies of the condensed $\mathrm{Al}$ and $\mathrm{Al}_{2} \mathrm{O}_{3}$ (namely, $e_{p k, \mathrm{Al}}$ and $e_{p k, \mathrm{Al}_{2} \mathrm{O}_{3}}$ ) presented in Eq. (3) are calculated from the particle temperature with latent heats of phase transition through the nine-coefficient NASA polynomial representation as well. The consumption rates of $\mathrm{O}_{2}$ and $\mathrm{Al}$ and the production rate of $\mathrm{Al}_{2} \mathrm{O}_{3}$ of the $k$ th particle due to combustion (namely, the $I_{p k, \mathrm{O}_{2}}, I_{p k, \mathrm{Al}}$, and $I_{p k, \mathrm{Al}_{2} \mathrm{O}_{3}}$ ) are determined by the combustion model of a single $\mathrm{Al}$ particle that will be introduced in Sec. II.B.

Notably, the aluminum oxide is considered remain in the condensed state attached to the unburned $\mathrm{Al}$ part, according to the scanning electron microscope (SEM) micrographs (Fig. 1) of a burning $\mathrm{Al}$ particle quenched at different time after ignition [21]. Due to the complex morphology variation of each particle during the combustion process, the drag force acting on the $k$ th particle is modeled as follows $[\underline{8}, \underline{14}]$ :

$$
\left\{\begin{array}{l}
f_{x k}=\frac{\pi}{8} C_{D k}\left(d_{p k, \mathrm{Al}}^{2}+d_{p k, \mathrm{Al}_{2} \mathrm{O}_{3}}^{2}\right) \rho\left|V-V_{p k}\right|\left(u-u_{p k}\right) \\
f_{y k}=\frac{\pi}{8} C_{D k}\left(d_{p k, \mathrm{Al}}^{2}+d_{p k, \mathrm{Al}_{2} \mathrm{O}_{3}}^{2}\right) \rho\left|V-V_{p k}\right|\left(v-v_{p k}\right)
\end{array}\right.
$$

where the drag coefficient is

$$
C_{D k}= \begin{cases}\frac{24}{R e_{p k}}\left(1+\frac{1}{6} R e_{p k}^{2 / 3}\right), & \text { for } R e_{p k}<1000, \\ 0.424, & \text { for } R e_{p k} \geq 1000\end{cases}
$$

And,

$$
\left|V-V_{p k}\right|=\left[\left(u-u_{p k}\right)^{2}+\left(v-v_{p k}\right)^{2}\right]^{1 / 2}
$$

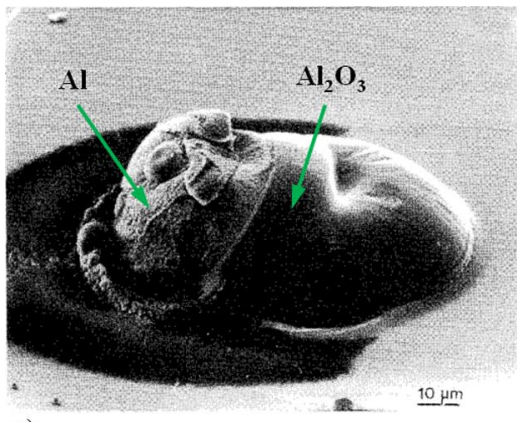

a)

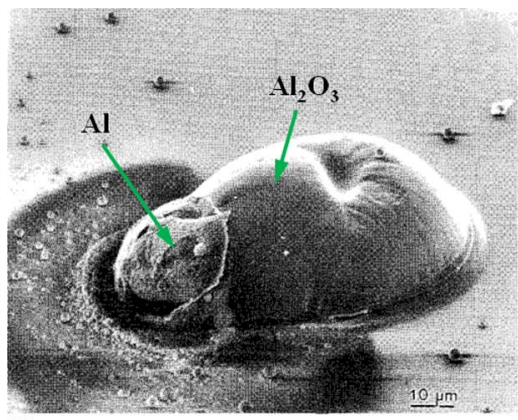

b)

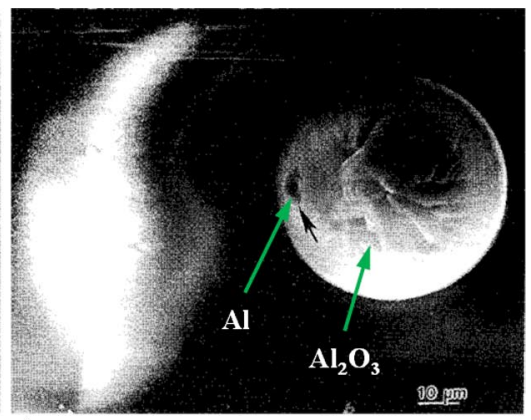

c) 


$$
R e_{p k}=\frac{\rho\left(d_{p k, \mathrm{Al}}+d_{p k, \mathrm{Al}_{2} \mathrm{O}_{3}}\right)\left|V-V_{p k}\right|}{\mu}
$$

In addition, the viscosity coefficient of gas is calculated by Sutherland's law:

$$
\mu=\frac{C_{1} T^{2 / 3}}{T+C_{2}}
$$

where $C_{1}=1.458 \times 10^{-6} \mathrm{~kg} /(\mathrm{m} \cdot \mathrm{s})$ and $C_{2}=110.4 \mathrm{~K}$ for air. Notably, comparing to the change with temperature, the variation of viscosity coefficient caused by the consumption of $\mathrm{O}_{2}$ is rather small (less than 4\%) and can be neglected. Therefore, Eq. (11) is used to evaluate the viscosity coefficient for both pure air and that with $\mathrm{O}_{2}$ consumption.

Accordingly, the convection heat transfer between the gas and the $k$ th particle is expressed as follows $[\underline{8}, \underline{14]}$ :

$$
q_{p k}=\pi\left(d_{p k, \mathrm{Al}}+d_{p k, \mathrm{Al}_{2} \mathrm{O}_{3}}\right) \lambda N u_{p k}\left(T-T_{p k}\right)
$$

with

$$
N u_{p k}=2+0.459 \operatorname{Re}_{p k}^{0.55} \operatorname{Pr}^{0.33}
$$

where the Prandtl number Pr is set to be 0.72 , and the heat conduction coefficient of gas is calculated by

$$
\lambda=\frac{c_{p} \mu}{\operatorname{Pr}}
$$

The Lagrangian governing equation for the $k$ th particle is written as follows:

$$
\frac{\mathrm{d} \boldsymbol{L}_{p k}}{\mathrm{~d} t}=\boldsymbol{S}_{p k}
$$

where $\boldsymbol{L}_{p k}$ is the vector of the Lagrangian variables of the $k$ th particle, and $\boldsymbol{S}_{p k}$ is the corresponding vector of the source terms. $\boldsymbol{L}_{p k}$ and $\boldsymbol{S}_{p k}$ are expressed, respectively, as

$$
\boldsymbol{L}_{p k}=\left[\begin{array}{l}
m_{p k} \\
x_{p k} \\
y_{p k} \\
m_{p k} u_{p k} \\
m_{p k} v_{p k} \\
E_{p k}
\end{array}\right], \quad \boldsymbol{S}_{p k}=\left[\begin{array}{c}
I_{p k, \mathrm{Al}_{2} \mathrm{O}_{3}}-I_{p k, \mathrm{Al}} \\
u_{p k} \\
v_{p k} \\
f_{x k} \\
f_{y k} \\
e_{p k, \mathrm{Al}_{2} \mathrm{O}_{3}} I_{p k, \mathrm{Al}_{2} \mathrm{O}_{3}}-e_{p k, \mathrm{Al}} I_{p k, \mathrm{Al}}+q_{p k}
\end{array}\right]
$$

with the total mass and total internal energy of the $k$ th particle calculated by

$$
\left\{\begin{array}{l}
m_{p k}=m_{p k, \mathrm{Al}}+m_{p k, \mathrm{Al}_{2} \mathrm{O}_{3}} \\
E_{p k}=m_{p k, \mathrm{Al}} e_{p k, \mathrm{Al}}+m_{p k, \mathrm{Al}_{2} \mathrm{O}_{3}} e_{p k, \mathrm{Al}_{2} \mathrm{O}_{3}}
\end{array}\right.
$$

\section{B. Combustion Model}

In this study, considering the computational feasibility [23,24], the single-step global chemical reaction instead of the detailed chemical reaction mechanisms for a cloud of $\mathrm{Al}$ particles surrounded by gases is employed to model the combustion of $\mathrm{Al}$ particles, with the product $\mathrm{Al}_{2} \mathrm{O}_{3}$ presented as a solid state:

$$
2 \mathrm{Al}(\mathrm{s})+3 / 2 \mathrm{O}_{2}(\mathrm{~g}) \rightarrow \mathrm{Al}_{2} \mathrm{O}_{3}(\mathrm{~s})
$$

Notably, gaseous aluminum monoxide $[\mathrm{AlO}(\mathrm{g})]$ is always experimentally found in the products of $\mathrm{Al}$ particle combustion at ambient pressure. However, as indicated in Refs. [24-28], the production of
$\mathrm{AlO}$ is significant if the gas temperature is higher than the decomposition temperature $\left(T_{g}>T_{\mathrm{dec}}\right)$, and the decomposition temperature $T_{\mathrm{dec}}$ is dependent on pressure via the Clausius-Clapeyron equation $[24,27,28]$ as follows:

$$
T_{\mathrm{dec}}=\frac{1}{2.50501 \times 10^{-4}-1.4132 \times 10^{-5} \cdot \ln \left(p_{\mathrm{atm}}\right)}
$$

where $p_{\text {atm }}$ is evaluated by the unit of $1 \mathrm{~atm}\left(=1.01325 \times 10^{5} \mathrm{~Pa}\right)$. As for Al-air two-phase detonation problems, the pressure behind the detonation front (where $\mathrm{Al}$ particles are fast burnt) is very high (greater than $60 \mathrm{~atm}$ in this study). As a result, $T_{\mathrm{dec}}$ is larger than $5000 \mathrm{~K}$. Nevertheless, the maximum temperature reached in this study is about $4000 \mathrm{~K}$ (i.e., $T_{g}<T_{\mathrm{dec}}$ at the corresponding pressure). Therefore, $\mathrm{AlO}$ would not be generated to a significant amount, and it is not considered in this paper. Moreover, the single-step global combustion model of Al particles has been well developed, and it is successful in

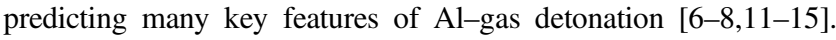
Then, the reaction heat release is implicitly given by the formation enthalpies of $\mathrm{Al}, \mathrm{O}_{2}$, and $\mathrm{Al}_{2} \mathrm{O}_{3}$. From Eq. (18), one can obtain

$$
\left\{\begin{array}{l}
I_{p k, \mathrm{Al}}+I_{p k, \mathrm{O}_{2}}=I_{p k, \mathrm{Al}_{2} \mathrm{O}_{3}} \\
\frac{I_{p k, \mathrm{Al}}}{\nu_{\mathrm{Al}} W_{\mathrm{Al}}}=\frac{I_{p k, \mathrm{O}_{2}}}{\nu_{\mathrm{O}_{2}} W_{\mathrm{O}_{2}}}=\frac{I_{p k, \mathrm{Al}_{2} \mathrm{O}_{3}}}{\nu_{\mathrm{Al}_{2} \mathrm{O}_{3}} W_{\mathrm{Al}_{2} \mathrm{O}_{3}}}
\end{array}\right.
$$

where $I_{p k, A l}$ can be decided by the combustion rate of the $k$ th $\mathrm{Al}$ particle; and $\nu_{\mathrm{Al}}, \nu_{\mathrm{O}_{2}}$, and $\nu_{\mathrm{Al}_{2} \mathrm{O}_{3}}$ are the stoichiometric coefficients for $\mathrm{Al}, \mathrm{O}_{2}$, and $\mathrm{Al}_{2} \mathrm{O}_{3}$ in Eq. (20), respectively.

It is experimentally found that (for example, Refs. [27,29]), for large Al particles $\left(d_{p}>10 \mu \mathrm{m}\right)$, the combustion rate is mainly limited by the diffusion processes of reactants and products, resulting in the diffusion-controlled combustion regime of $\mathrm{Al}$ particles. Contrarily, other experimental observations [30-32] indicate that, for small Al particles $\left(d_{p}<1 \mu \mathrm{m}\right)$, the combustion rate is limited by the kinetic oxidation reaction on the surface, consequently yielding the kinetic-controlled combustion regime of Al particles. Since the Al particle sizes considered in this study are within the kineticcontrolled and diffusion-controlled combustion regimes (for the monodisperse suspension, $d_{p}=2 \mu \mathrm{m}$; and for the polydisperse suspensions, $d_{p} \sim 0.1-5 \mu \mathrm{m}$ ), the surface-kinetic-oxidation and diffusion hybrid combustion model (originally proposed by Zhang and Gerrard [8]) is employed to model the combustion rate for every single $\mathrm{Al}$ particle. This model, which can capture both the kineticcontrolled combustion regime for fine $\mathrm{Al}$ particles and the diffusioncontrolled combustion regime for large $\mathrm{Al}$ particles, depends on temperature, pressure, and the particle size. In the low-temperature regime, the combustion rate in this hybrid model is dominated by the kinetic reaction rate, which is characterized by an Arrhenius-type equation. The combustion rate is zero at low temperature and exponentially increases once the temperature reaches the "particle ignition temperature" that is related to the activation energy. Therefore, an artificially assumed particle ignition temperature is not needed in the hybrid combustion model [33]. The Lagrangian form of $\mathrm{Al}$ combustion rate can be easily derived from the original Eulerian form as follows:

$$
I_{p k, \mathrm{Al}}=\pi d_{p k, \mathrm{Al}}^{2} C_{\mathrm{O}_{2}} \frac{\nu_{\mathrm{Al}} W_{\mathrm{Al}}}{\nu_{\mathrm{O}_{2}} W_{\mathrm{O}_{2}}} \cdot \frac{k_{d k} k_{s k}}{k_{d k}+k_{s k}}
$$

For the diffusion-controlled combustion regime of Al particles []ㅡ, the reaction rate $k_{d k}$ is

$$
k_{d k}=\frac{\nu_{\mathrm{O}_{2}} W_{\mathrm{O}_{2}}}{\nu_{\mathrm{Al}} W_{\mathrm{Al}}} \frac{\rho_{\mathrm{Al}} d_{p k, \mathrm{Al}}}{2 C_{\mathrm{total}} K d_{p k 0, \mathrm{Al}}^{2}}\left(1+0.276 \operatorname{Re}_{p k}^{1 / 2} \operatorname{Pr}^{1 / 3}\right)
$$

And, for the kinetic-controlled combustion regime of $\mathrm{Al}$ particles, the reaction rate $k_{s k}$ is 
Table 1 Comparison of calculated wave velocities and peak pressures of monodisperse Al-air detonation with experiments ${ }^{\mathrm{a}}$

\begin{tabular}{|c|c|c|c|c|c|}
\hline & & \multicolumn{2}{|c|}{ Experimental values [30] } & \multicolumn{2}{|c|}{ Calculation in this paper } \\
\hline & & $D(\mathrm{~m} / \mathrm{s})$ & $p_{\max } / p_{0}$ & $D(\mathrm{~m} / \mathrm{s})$ & $p_{\max } / p_{0}$ \\
\hline$d_{p}=2 \mu \mathrm{m}$ & $500 \mathrm{~g} / \mathrm{m}^{3} \cdot \operatorname{atm}(\mathrm{ER}=1.63)$ & $1460-1500$ & $26.0-28.4$ & 1535 & 27.25 \\
\hline$p_{0}=2.5 \mathrm{~atm}$ & $600 \mathrm{~g} / \mathrm{m}^{3} \cdot \operatorname{atm}(\mathrm{ER}=1.95)$ & $1430-1465$ & -- & 1449 & 25.52 \\
\hline$d_{p}=0.1 \mu \mathrm{m}$ & $400 \mathrm{~g} / \mathrm{m}^{3} \cdot \operatorname{atm}(\mathrm{ER}=1.30)$ & $1611-1699$ & $35.0-37.6$ & 1762 & 37.16 \\
\hline$p_{0}=1.5 \mathrm{~atm}$ & $500 \mathrm{~g} / \mathrm{m}^{3} \cdot \operatorname{atm}(\mathrm{ER}=1.63)$ & $1560-1630$ & -- & 1546 & 30.87 \\
\hline
\end{tabular}

${ }^{\mathrm{a} E R}$ denotes equivalence ratio.

$$
k_{s k}=k_{0} e^{-E_{a} / R_{0} T_{s k}}
$$

where $T_{s k}$ is the particle surface temperature. In the work of Zhang and Gerrard [8], the average of the gas temperature and particle temperature is used to model $T_{s k}$ [i.e., $T_{s k}=\left(T+T_{p k}\right) / 2$ ] to take thermal nonequilibrium between the particle and its surrounding gas into account. The constants in Eqs. (22) and (23) are $K=4 \times 10^{6} \mathrm{~s} / \mathrm{m}^{2}$, $k_{0}=1200 \mathrm{~kg} \cdot \mathrm{m} /(\mathrm{mol} \cdot \mathrm{s})$, and $E_{a}=71.1 \mathrm{~kJ} / \mathrm{mol}$, which are given as those in the previous papers $[8,14]$. With the proposed combustion model and the usage of the average of the gas temperature and particle temperature to calculate the kinetic combustion rate, Zhang and Gerrard [8] observed the same rotation periods in their numerical simulations with their rotating detonation tube experiments. In the current study, simulations with the average of the gas temperature and particle temperature also present experiment-consistent results, which are detonation speeds and peak pressures in Table 1 (see Sec. III.A). Therefore, the usage of the average of the gas temperature and particle temperature to evaluate the kinetic rate in the hybrid combustion model of $\mathrm{Al}$ particles seems reasonable and is indirectly justified.

\section{Particle Size Distribution}

In reality, Al-gas suspension is always polydispersed with a specific particle size distribution. To compare and analyze the effects of the particle size distribution on Al-gas detonation, and to present some comparative results to the previous numerical simulations with monodisperse suspension, two Al-air suspensions with different particle size distributions are considered here. One is monodisperse, which is employed in most previous numerical simulations. The other is polydisperse with a log-normal distribution, which is frequently used to represent the sizes of solid particles [20]. The log-normal distribution, derived from the normal distribution by replacing the independent variable with the logarithm of the particle diameter, can be expressed by the number frequency distribution function $f_{n}\left(d_{p}\right)$ as follows:

$$
f_{n}\left(d_{p}\right)=\frac{1}{\sqrt{2 \pi} \sigma_{0}} \exp \left[-\frac{1}{2}\left(\frac{\ln d_{p}-\ln d_{\mathrm{nM}}}{\sigma_{0}}\right)^{2}\right] \frac{1}{d_{p}}
$$

where $d_{\mathrm{nM}}$ and $\sigma_{0}$ are the number median diameter and standard deviation of the distribution, respectively. Then, particle diameters in the polydisperse $\mathrm{Al}$ suspension are set by a random number generator with Eq. (24) in the numerical simulations. Additionally, these particles are set to be uniformly distributed in the computation domain with the same particle number density as in the monodisperse suspension.

The same case as described in the Al-gas detonation experiment of Zhang et al. [30] is studied. The test material is a micrometric grade of atomized $\mathrm{Al}$ with a nominal diameter (volume-average diameter $\bar{d}$ ) of $2 \mu \mathrm{m}$, known as H-2, supplied by Valimet Incorporated. An important relationship for the calculation of various mean diameters of log-normal distribution is

$$
\int_{0}^{\infty} s^{k} f_{n}(s) \mathrm{d} s=d_{\mathrm{nM}}^{k} e^{\sigma_{0}^{2} k^{2} / 2}
$$

where $s$ is the integration variable. As indicated in Ref. [8], another parameter describing the test materials is the mass-weighted-average particle diameter $\bar{d}_{m}=3.3 \mu \mathrm{m}$. The $\bar{d}$ and $\bar{d}_{m}$ can be calculated by integrations of $f_{n}\left(d_{p}\right)$ with Eq. (25):

$$
\left\{\begin{array}{l}
\bar{d}=\left[\int_{0}^{\infty} s^{3} f_{n}(s) \mathrm{d} s\right]^{1 / 3}=d_{\mathrm{nM}} e^{(3 / 2) \sigma_{0}^{2}} \\
\bar{d}_{m}=\left[\int_{0}^{\infty} s^{4} f_{n}(s) \mathrm{d} s\right] /\left[\int_{0}^{\infty} s^{3} f_{n}(s) \mathrm{d} s\right]=d_{\mathrm{nM}} e^{(7 / 2) \sigma_{0}^{2}}
\end{array}\right.
$$

which yields $d_{\mathrm{nM}}=1.37 \mu \mathrm{m}$ and $\sigma_{0}=0.50$. The distribution of this test material is shown in Fig. 2 by the number frequency distribution function defined in Eq. (24). For comparison, log-normal distributions with fixed $\bar{d}=2 \mu \mathrm{m}$ but different $\sigma_{0}$ are also presented in Fig. 2 . All distributions shown in Fig. 2 are simulated in this paper, but the main distribution discussed is the one with $\sigma_{0}=0.5$.

\section{Computational Domain and Initial Allocation of Particles}

The computational domains of the 1-D and 2-D conservation element (CE)/solution element (SE) simulations are $6 \mathrm{~m}$ in length $(x)$ and $1.6 \mathrm{~m}$ in length $(x) \times 0.1 \mathrm{~m}$ in width $(y)$, respectively. The grid independence tests will be elaborated on in Sec. III.A. Actually, as shown in Fig. 3 , the 1-D/2-D computation domain for CE/SE Eulerian simulations is considered here as an equivalent three-dimensional (3-D) zone when solving the Lagrangian governing equations for the particles [Eqs. (15-17)]. To correctly represent the monodisperse/ polydisperse distribution in 1-D/2-D simulations, $d V$ (the volume of the equivalent 3-D computational mesh) in Eq. (3) needs to be properly chosen. For the Al-air mixture studied in this work (with $\bar{d}=2 \mu \mathrm{m}$ and $C_{p}=1.25 \mathrm{~kg} / \mathrm{m}^{3}$ ), the corresponding particle number density is about $1.1 \times 10^{14} / \mathrm{m}^{3}$, which yields a mean interparticle distance of $\Delta h=20.84 \mu \mathrm{m}$. Therefore, the cross-section area $(y-z$ plane) in the 1-D simulations with the monodisperse suspension is set to be $20.84 \times 20.84 \mu \mathrm{m}^{2}$, which ensures that only one Al particle is included on the cross section exactly (Fig. 3a). In other words, only one row of $\mathrm{Al}$ particles is included in the equivalent 3-D computation domain $(d V=20.84 \mu \mathrm{m} \times 20.84 \mu \mathrm{m} \times \Delta x$, where $\Delta x$ is the 1-D mesh size and $\Delta x=0.05 \mathrm{~mm}$ in this study). There are about 48 particles per millimeter, which are uniformly distributed along this

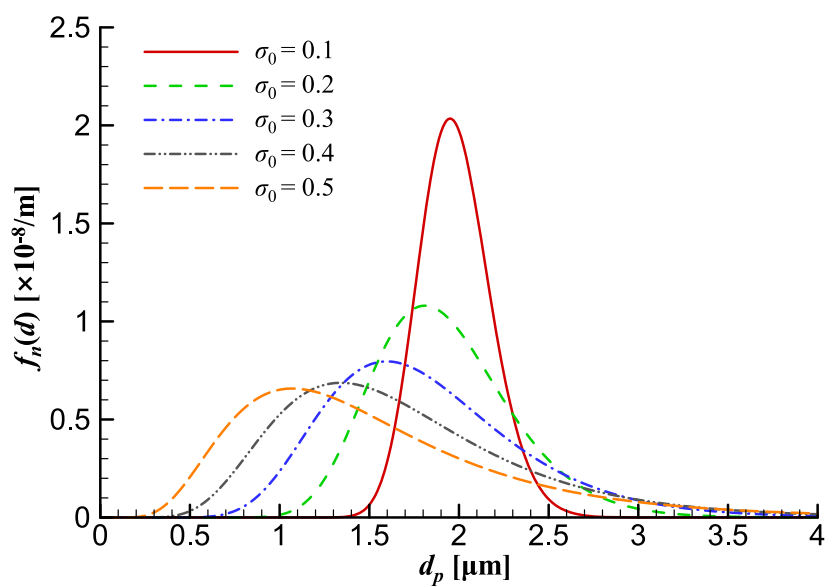

Fig. 2 Log-normal particle size distributions with $\bar{d}=2 \mu \mathrm{m}$. 


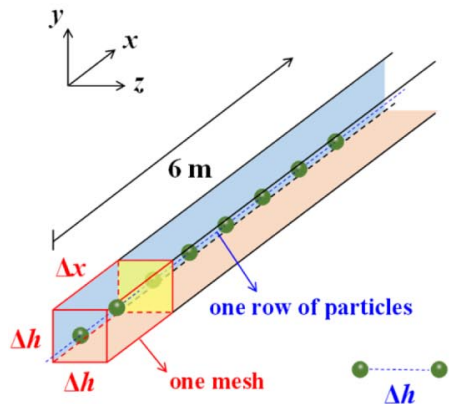

a)

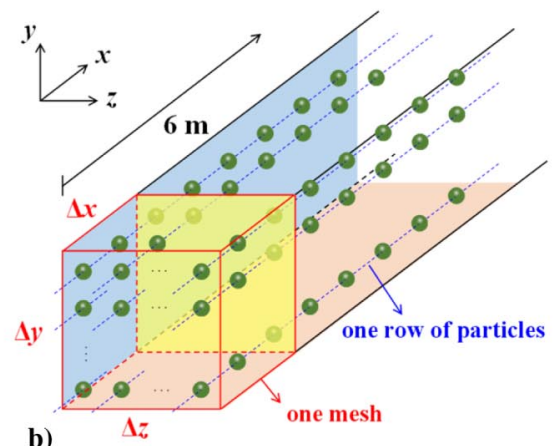

b)

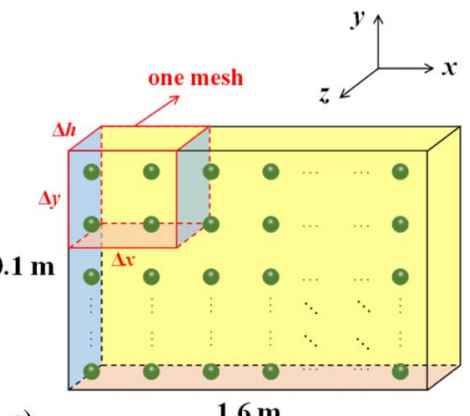

c)

$1.6 \mathrm{~m}$

Fig. 3 Deployment of particles and equivalent 3-D computational zones for a) 1-D monodisperse simulation, b) 1-D polydisperse simulation, and c) 2-D monodisperse/polydisperse simulation. (A green circle represents a particle.)

row $(\Delta h=20.84 \mu \mathrm{m}$ in $x$ direction). On the other hand, for 1-D simulations with the polydisperse suspension, the equivalent crosssection area $(y-z$ plane $)$ is set to be $0.66 \times 0.66 \mathrm{~mm}^{2}$, which ensures about $1000 \mathrm{Al}$ particles with the log-normal particle size distribution [Eq. (24)] included on the cross section (Fig. 3b). The particles of different diameters in the polydisperse $\mathrm{Al}$ suspension are distributed uniformly $(\Delta h=20.84 \mu \mathrm{m})$ in the equivalent 3-D computation domain $(d V=0.66 \mathrm{~mm} \times 0.66 \mathrm{~mm} \times \Delta x$, and $\Delta x=0.05 \mathrm{~mm}$ in this study). And, the diameter of each particle is determined by a random number generator. In these 1-D simulations, the rigid wall condition is set at the left end of the computational domain, whereas an outlet condition is set at the right end.

As for the 2-D simulations (Fig. 3c), since there are already about 2300 particles per square millimeter in one layer of particles ( $x-y$ plane), isotropic gas-particle suspensions with log-normal particle size distributions can be guaranteed in the 2-D computational domain of $1.6 \mathrm{~m}(x) \times 0.1 \mathrm{~m}(y)$. Therefore, for both monodisperse and polydisperse suspensions, $d V=\Delta x \times \Delta y \times 20.84 \mu \mathrm{m}$ and $\Delta x=$ $\Delta y=0.05 \mathrm{~mm}$. Just one layer of Al particles is included in the equivalent domain. Again, for monodisperse/polydisperse suspension cases, the particles are uniformly distributed $(\Delta h=20.84 \mu \mathrm{m})$ on the $x-y$ plane, as in the 1-D simulations. As for boundary conditions of 2-D computations, the left end is set as a rigid wall, the upper and lower sides are set as slip boundaries, and the right end is set as the outlet condition.

\section{E. Numerical Algorithm}

In this study, our in-house 2-D space-time conservation element and solution element method based on quadrilateral meshes is used to solve the gaseous Euler equations $[33,34]$. The CE/SE method, originally proposed by Chang [35], uses a unique approach of enforcing flux conservation in both space and time with extensive physics consideration, and hence is a robust high-resolution shockcapturing method to solve hyperbolic conservation laws in highspeed reactive flows [36,37] and multiphase flows [38-40].

The stiff source terms of $\mathrm{Al}$ combustion and phase interactions as well as the Lagrangian equations of particles are explicitly integrated as ordinary differential equations by using an operator-splitting technique with multiple subtime steps [41]. The detailed implementation can be illuminated through where the subscripts $n$ and $m$ refer to the global time step and the subtime step, respectively; and $N$ is the number of subtime steps within one global convection time step of gaseous Euler equations. $N$ is chosen to be 10 for the following simulations, which have been carefully validated by convergence tests. More details about the physical models and numerical methods can be found in our recent paper [33].

\section{Results and Discussion}

\section{A. Validation and Resolution Tests}

In this section, the numerical code with the aforementioned models and methods is validated by comparing the calculated 1-D monodisperse Al-air detonation with the experiments of Zhang et al. [30]. More validation cases of the code can be also found in Ref. [33], such as 1) the comparison of 1-D inert gas-particle shock tube problems with those numerically obtained by Saito et al. [42], and 2) the comparison of 2-D Al-gas detonation cellular structures with those experimentally obtained by Zhang et al. [4] and Ingignoli et al. [43]. The material used is a micrometric grade of atomized Al with a nominal diameter of $2 \mu \mathrm{m}$. The dust concentration of the Al-air mixture is $C_{p}=1.25 \mathrm{~kg} / \mathrm{m}^{3}$, and the initial pressure and temperature are $p_{0}=2.5$ atm and $T_{0}=300 \mathrm{~K}$, respectively. This experimental setting of Zhang et al. [30] is the main case discussed in this paper unless otherwise stated. The detonation is directly initiated by a small zone of high temperature and pressure at the left end of the computational domain. The mesh size in the direction of the detonation travelling ( $x$ direction) is $0.05 \mathrm{~mm}$, which will be validated by convergence tests later in this section. Figures $4 \mathrm{a}$ and $4 \mathrm{~b}$ present the time evolution of pressure distribution along the 1-D computational domain for time instants from 0.4 to $3.6 \mathrm{~ms}$ with an interval of $0.4 \mathrm{~ms}$ and the time evolution of the detonation velocity, respectively. It can be revealed that the detonation reaches a nearly steady state at $t=1 \mathrm{~ms}$ after initiation. The calculated 1-D detonation velocity is equal to $D=1535 \mathrm{~m} / \mathrm{s}$ at $t=3.6 \mathrm{~ms}$ and is slightly lower than the theoretical Chapman-Jouguet (CJ) detonation velocity of $D_{\mathrm{CJ}}=1539 \mathrm{~m} / \mathrm{s}$. As indicated in Fig. 4b, it can be expected that this slight difference would be smaller and smaller as the simulation proceeds, and the final stable detonation velocity would be equal to the theoretical value. The peak pressure is equal to $p_{\max } / p_{0}=27.25$.

$$
\boldsymbol{U}_{n} \underset{S=0}{\mathrm{Eq}(1)} \tilde{\boldsymbol{U}}_{n+1} \Rightarrow\left\{\begin{array} { l } 
{ d t = N d t ^ { \prime } } \\
{ \boldsymbol { U } _ { n + 1 } ^ { ( 0 ) } = \tilde { \boldsymbol { U } } _ { n + 1 } } \\
{ \boldsymbol { L } _ { p k , n + 1 } ^ { ( 0 ) } = \boldsymbol { L } _ { p k , n } }
\end{array} \Rightarrow \left\{\begin{array} { l } 
{ \boldsymbol { U } _ { n + 1 } ^ { ( m ) } , \boldsymbol { L } _ { p k , n + 1 } ^ { ( m ) } \rightarrow \boldsymbol { S } ^ { ( m ) } , \boldsymbol { S } _ { p k } ^ { ( m ) } } \\
{ \boldsymbol { U } _ { n + 1 } ^ { ( m + 1 ) } = \boldsymbol { U } _ { n + 1 } ^ { ( m ) } + d t ^ { \prime } \boldsymbol { S } ^ { ( m ) } } \\
{ \boldsymbol { L } _ { p k , n + 1 } ^ { ( m + 1 ) } = \boldsymbol { L } _ { p k , n + 1 } ^ { ( m ) } + d t ^ { \prime } \boldsymbol { S } _ { p k } ^ { ( m ) } }
\end{array} \Rightarrow \left\{\begin{array}{l}
\boldsymbol{U}_{n+1}=\boldsymbol{U}_{n+1}^{(\mathrm{N})} \\
\boldsymbol{L}_{p k, n+1}=\boldsymbol{L}_{p k, n+1}^{(\mathrm{N})}
\end{array}\right.\right.\right.
$$



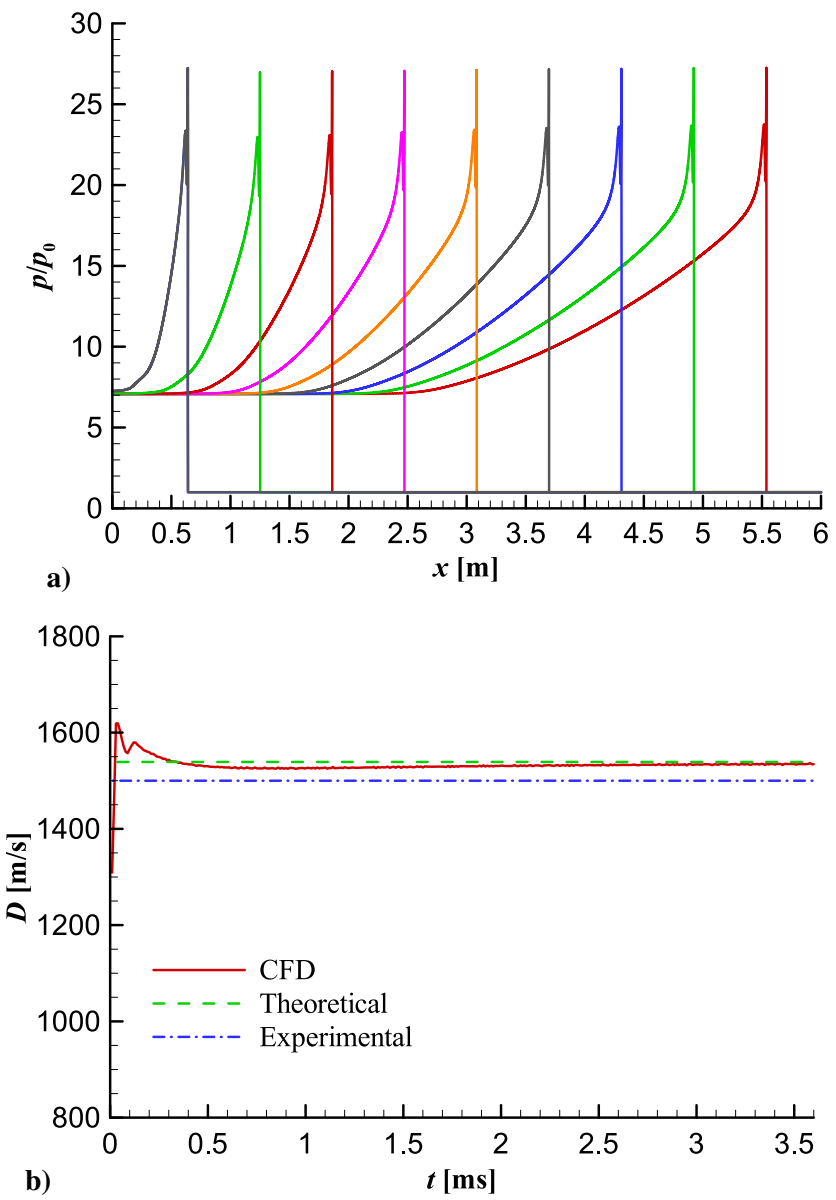

Fig. 4 Monodisperse Al-air detonation with $\bar{d}=2 \mu \mathrm{m}$ $(\Delta x=0.05 \mathrm{~mm})$ : time evolution of a) pressure distribution at $t=0.4$, $0.8, \ldots, 3.6 \mathrm{~ms}$, and b) detonation velocity. CFD denotes computational fluid dynamics.

Three other cases in the experiments of Zhang et al. [30] are calculated here as well, and the results are summarized in Table 1 . It can be seen that the calculated detonation velocities agree with the experimental ones for all these cases, and the maximum difference with the experimental mean value is about $6.5 \%$. Additionally, the calculated peak pressures agree quite well with the experimental ones.

Notably, the preceding calculation results are based on the monodisperse suspension. As discussed later in Sec. III.C, the calculated 1-D detonation velocity and peak pressure of polydisperse suspension (of $\bar{d}=2 \mu \mathrm{m}$ and $500 \mathrm{~g} / \mathrm{m}^{3} \cdot \mathrm{atm}$ ) with a log-normal particle size distribution $\left(\sigma_{0}=0.5\right)$ are, respectively, $D=1560 \mathrm{~m} / \mathrm{s}$ and $p_{\max } / p_{0}=26.85$, which also agree well with the experiment ones. The detonation velocities and peak pressures do not differ much between monodisperse and polydisperse suspensions for the same case. Considering the measurement uncertainties in experiments, the numerical code is shown capable of capturing the main features of Al-air detonation.

To ensure the calculated Al-air detonation results are not affected by the grid resolution, convergence tests are performed carefully by using different mesh sizes for all cases presented in this paper. Taking the main case of this paper $\left(d_{p}=2 \mu \mathrm{m}, C_{p}=1.25 \mathrm{~kg} / \mathrm{m}^{3}\right.$, $p_{0}=2.5 \mathrm{~atm}$, and $T_{0}=300 \mathrm{~K}$ ) as an example, the pressure profiles for 1-D monodisperse Al-air detonation at $t=3.6 \mathrm{~ms}$ after initiation with different mesh size are shown in Fig. $\underline{5}$. As seen in the enlarged view, the difference near the leading shock (which is the key region discussed in this paper) is hardly noticeable when the mesh size is smaller than $0.2 \mathrm{~mm}$. Nevertheless, when detonation dynamics (such as instability and cellular detonation) are studied, a smaller mesh size should be adopted generally. Therefore, another convergence test under the same conditions as mentioned earlier in this paper is demonstrated by comparing the cell sizes of 2-D monodisperse

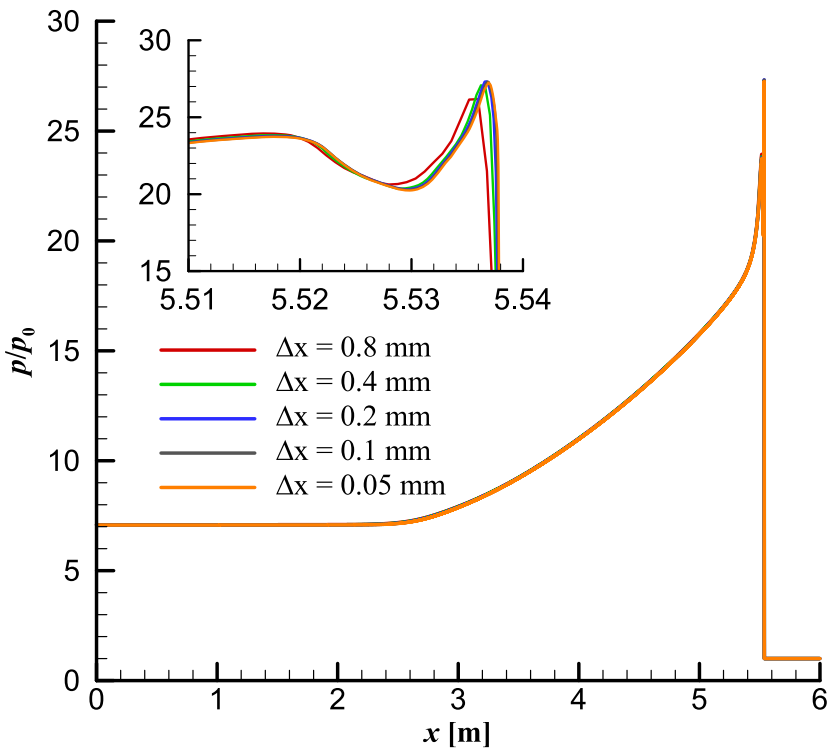

Fig. 5 Pressure profiles of $2 \mu \mathrm{m}$ monodisperse Al-air detonation at $t=3.6 \mathrm{~ms}$ with different mesh sizes.

Al-air detonation with different mesh sizes. In Fig. $\underline{6}$, the numbers of detonation cell in a channel of $10 \mathrm{~cm}$ width delineated by the peak pressure contours with mesh sizes of $0.1 \times 0.1 \mathrm{~mm}$, $0.05 \times 0.05 \mathrm{~mm}$, and $0.025 \times 0.025 \mathrm{~mm}$ are $5,9.5$, and 9.5 , respectively. The corresponding cell sizes $\lambda_{\text {monodisperse }}$ are 20.0, 10.5, and $10.5 \mathrm{~mm}$. As shown in Fig. 6 , the averaged cell sizes change dramatically when the mesh sizes decrease from 0.1 to $0.05 \mathrm{~mm}$; however, further refining the mesh size does not affect the cell size or cell regularity significantly. The grid independence tests are considered convergent at $\Delta x=\Delta y=0.05 \mathrm{~mm}$. Consequently, a mesh size of $0.05 \times 0.05 \mathrm{~mm}$ is chosen to calculate the Al-air detonation cell size for this 2-D monodisperse case. Notably, the mesh size of $0.05 \times 0.05 \mathrm{~mm}$ ensures that there are more than 200 meshes in one detonation cell in the simulation, which agrees with the convergence requirement (at least 100 mesh points per cell width) for the 2-D gaseous detonation suggested by Gavrikov et al. [44]. From the 1-D and 2-D convergence tests discussed earlier in this paper, the mesh size of $0.05 \mathrm{~mm}$ is used to simulate the main case in this work.

\section{B. Detonation in Monodisperse Suspensions}

Before analyzing the effects of particle size distribution, the multiphase characteristics and mechanism of monodisperse Al-air detonation by 1-D simulations will be briefly introduced first for the contextual clarity. As mentioned earlier in this paper, the Al-air detonation discussed here is the case of $d_{p}=2 \mu \mathrm{m}$, $C_{p}=1.25 \mathrm{~kg} / \mathrm{m}^{3}, p_{0}=2.5 \mathrm{~atm}$, and $T_{0}=300 \mathrm{~K}$. The structures of the monodisperse $\mathrm{Al}$-air detonation front at $t=2 \mathrm{~ms}$ are shown in Fig. 7, from which some special features of heterogeneous detonation corresponding to multiphase interactions can be easily recognized. The first feature is known as "double peaks" in the gas pressure, density, and velocity profiles (Figs. 7a and 7c), which is distinctly different from the single peak feature observe $\bar{d}$ in gaseous detonation. The formation mechanism of this double peaks feature in the monodisperse $\mathrm{Al}$-air detonation front is due to the competition among the Al particle combustion, gas-particles heat transfer, and gas-particles momentum transfer processes (the detailed aerothermodynamic mechanism will be discussed later in this section). The second feature, shown in Fig. 7b, is the plateau of particle temperature due to $\mathrm{Al}$ evaporation, which is equal to $2750 \mathrm{~K}$ and results in the observed "kink" in the gas temperature profile due to the intense heat transfer between gas and particles. The third feature, shown in Fig. 7c, is the particle velocity lag in the velocity relaxation process, resulting in the alternative forces acting on particles and momentum transfers between gas and particles. All these two-phase features for 


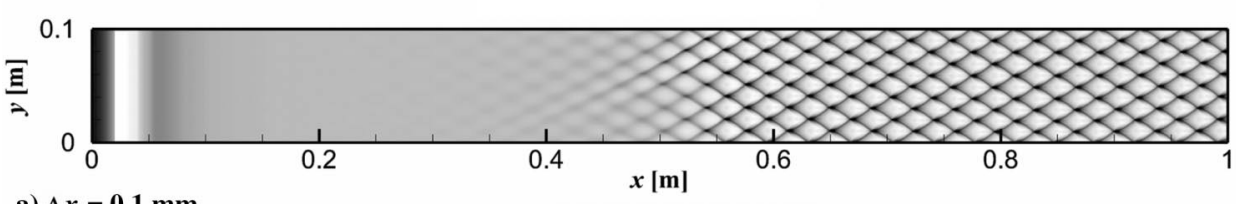

a) $\Delta x=0.1 \mathrm{~mm}$
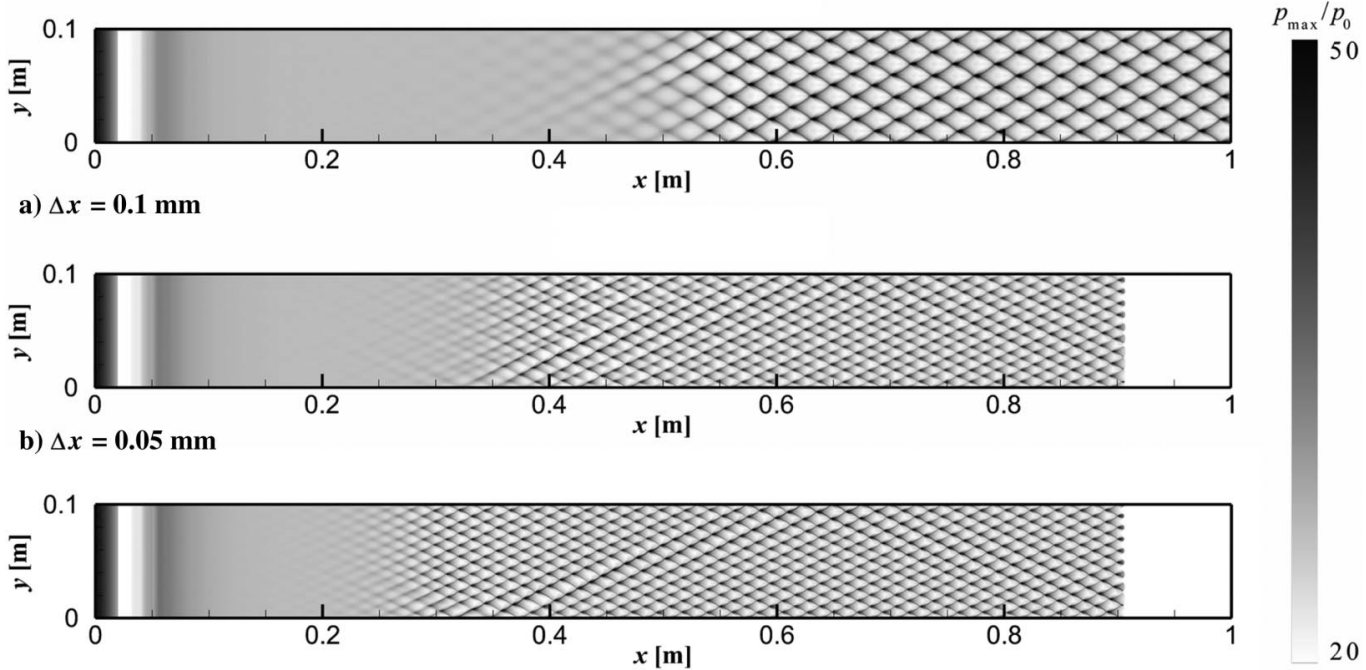

c) $\Delta x=0.025 \mathrm{~mm}$

Fig. 6 Cellular detonations (peak pressure contours) of $2 \mu \mathrm{m}$ monodisperse Al-air mixture with different mesh sizes: a) $\Delta x=\Delta y=0.1 \mathrm{~mm}$ and $\left.\lambda_{\text {monodisperse }}=20 \mathrm{~mm}, \mathrm{~b}\right) \Delta x=\Delta y=0.05 \mathrm{~mm}$ and $\lambda_{\text {monodisperse }}=10.5 \mathrm{~mm}$, and c) $\Delta x=\Delta y=0.025 \mathrm{~mm}$ and $\lambda_{\text {monodisperse }}=10.5 \mathrm{~mm}$. $\lambda_{\text {monodisperse }}$ is simulated average cell size.

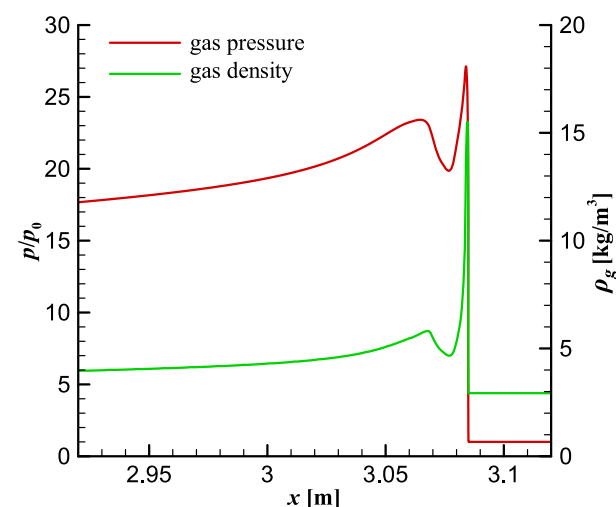

a)

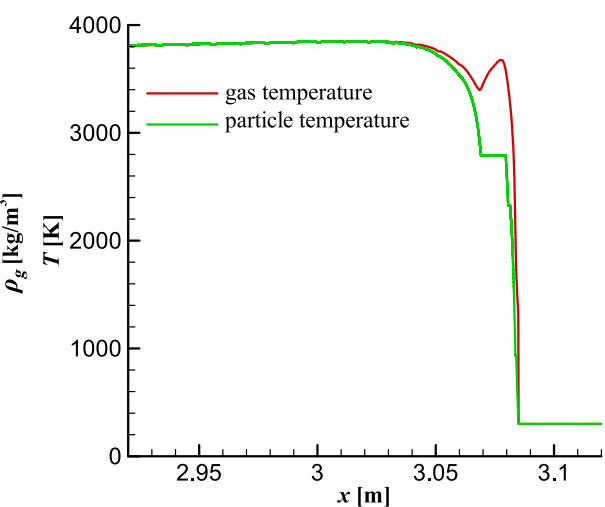

b)

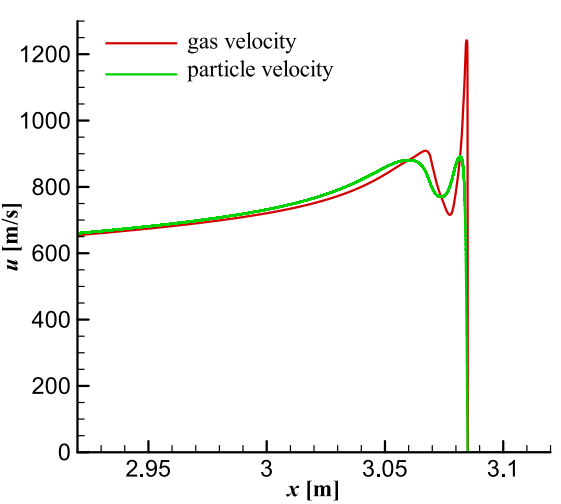

c)

Fig. 7 Structures of monodisperse Al-air detonation front at $t=2 \mathrm{~ms}$ : a) gas pressure and density, b) temperature of gas and particles, and c) velocity of gas and particles.

monodisperse Al-air detonation are similar to those obtained by Zhang [5], Zhang and Gerrard [8], and Teng and Jiang [14,15].

Note that the aforementioned special features in $\mathrm{Al}$-air detonation are the results of competition among different mechanisms, including combustion (consisting of mass transfer and reaction heat release), heat transfer (due to gas-particles temperature nonequilibrium), and momentum transfer (due to the gas-particles relative velocity). To decouple these three kinds of gas-particles interactions, the evaluations of their corresponding effects on the gas pressure change behind the detonation front can be derived from the one-dimensional flow theory in gas dynamics [ㄴ5]:

$$
\left\{\begin{array}{l}
-\left.\frac{1}{p} \frac{\mathrm{d} p}{\mathrm{~d} x}\right|_{r}=\frac{\gamma M^{2}}{M^{2}-1}\left(\frac{\dot{Q}_{r}}{\rho c_{p} T}+\frac{\dot{\rho}}{\rho}\right) \cdot \frac{1}{U} \\
-\left.\frac{1}{p} \frac{\mathrm{d} p}{\mathrm{~d} x}\right|_{q}=\frac{\gamma M^{2}}{M^{2}-1} \cdot \frac{\dot{Q}_{q}}{\rho c_{p} T} \cdot \frac{1}{U} \\
-\left.\frac{1}{p} \frac{\mathrm{d} p}{\mathrm{~d} x}\right|_{m}=\frac{\gamma M^{2}\left[1+(\gamma-1) M^{2}\right]}{M^{2}-1} \cdot \frac{f}{\rho U} \cdot \frac{1}{U}
\end{array}\right.
$$

where the subscripts $r, q$, and $m$ in the derivatives of pressure refer to the contributions of combustion, heat transfer, and momentum transfer, respectively. $\dot{Q}_{r}, \dot{\rho}, \dot{Q}_{q}$, and $f$ are the rates of reaction heat released to, mass transferred to, heat transferred to, and force acted on gas per unit volume, respectively, and have the following forms [derived from Eq. (ㄱ)]:

$$
\left\{\begin{array}{l}
\dot{Q}_{r}=-\sum_{1}^{N p}\left(e_{p k, \mathrm{Al}_{2} \mathrm{O}_{3}} I_{p k, \mathrm{Al}_{2} \mathrm{O}_{3}}-e_{p k, \mathrm{Al}} I_{p k, \mathrm{Al}}\right) / d V \\
\dot{\rho}=-\sum_{1}^{N p} I_{p k, \mathrm{O}_{2}} / d V \\
\dot{Q}_{q}=-\sum_{1}^{N p} q_{p k} / d V \\
f=-\sum_{1}^{N p} f_{x k} / d V
\end{array}\right.
$$

$U$ and $M$ are the gas velocity and corresponding Mach number in the front-fitted coordinate system, respectively. The results are shown in Fig. 8 with the coordinate $x$ originating at the detonation front. The total effect curve in Fig. $8 \mathrm{a}$ is simply calculated by summation of the effects of combustion, heat transfer, and momentum transfer.

After the shock compression and before the CJ state, three zero points are observed in the total effect curve and divide the changing of gas pressure into four stages. Stage 1 begins from the von Neumann state just after the shock front, where the gas is accelerated to a very high velocity by shock compression but the velocity of particles remains very low due to their inertia. The increase of gas pressure is mainly due to the fast velocity relaxation process and the resulting drag compression of particles with large relative velocity between 


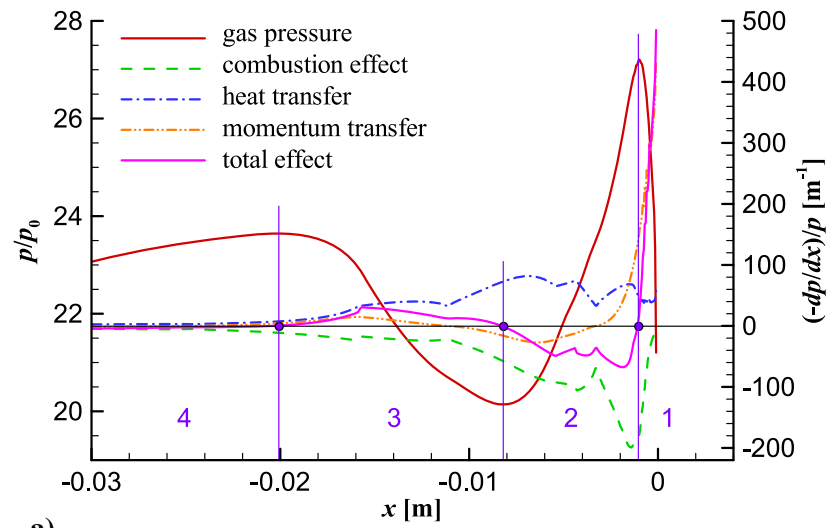

a)

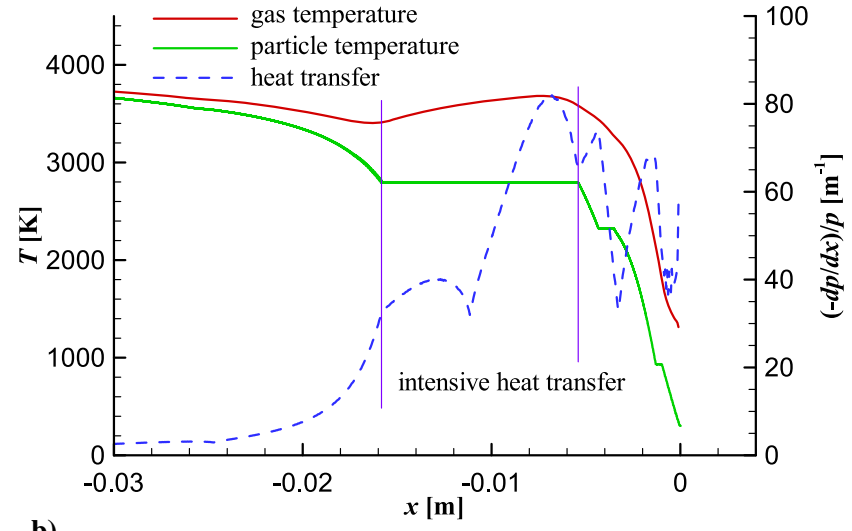

b)

Fig. 8 Effects of combustion, heat transfer, and momentum transfer on a) gas pressure in monodisperse $\mathrm{Al}$-air detonation and b) comparison with temperatures.

particles and gas. The effect of momentum transfer is much larger than that of combustion and heat transfer in this stage. After stage 1, when the velocity relaxation drops significantly and the combustion of Al particles becomes substantial, detonation enters a fast combustion period, causing the decrease of gas pressure in stage 2 . In stage 3 , which is the middle period of combustion, the intensity of combustion becomes weaker, whereas the intensity of heat transfer remains relatively large. The dominating effect of heat transfer in this stage produces the increase of gas pressure again. At the end of stage 3, the intensities of heat transfer and momentum transfer rapidly decay to nearly zero, which cause the weak effect of combustion to become dominant in stage 4. As a result, the gas pressure decreases again.
Apparently, the existence of stage 3, which is dominated by heat transfer, is the reason for the appearance of the second peak in the detonation front structures of monodisperse $\mathrm{Al}$ suspension.

Further analysis of the heat transfer curve and its comparison with the temperature curves are shown in Fig. 8b. The data reveal that the intense heat transfer is mainly caused by the large temperature difference between gas and particles when the particle phase transition intensely occurs at a specific location after the shock front with particle temperature at a constant value. As a result, the enduring evaporation of $\mathrm{Al}$ induces the intense heat transfer for a long time, even when the intensity of combustion becomes weak. This dominant stage of heat transfer (stage 3) provides an insight into the double peaks feature.

Additional simulations for monodisperse Al-air suspensions with particle diameters ranging from 0.5 to $10 \mu \mathrm{m}$ (Fig. 9) show that the double peaks always occur in the pressure profiles, despite different particle sizes, indicating that the dominant heat transfer stage (stage 3) prevails in monodisperse $\mathrm{Al}$-air detonation.

\section{Detonation in Polydisperse Suspensions}

As discussed in Sec. II.C, the log-normal distribution with $\bar{d}=$ $2 \mu \mathrm{m}$ and $\sigma_{0}=0.5$, corresponding to the statistical properties of the tested $\mathrm{H}-2 \mathrm{Al}$ in the experiments of Zhang et al. [30], is used to model the particle size distribution in simulations of polydisperse Al-air detonation. Except for the particle size distribution, all other conditions are the same as the simulations in Sec. III.B. Notably, the mesh size for these 1-D polydisperse detonation is still $\Delta x=0.05 \mathrm{~mm}$. In addition, the $1-\mathrm{D}$ computation domain considered here has a cross-section area of $0.66 \times 0.66 \mathrm{~mm}^{2}(y-z$ plane $)$ with one mesh, which results in about $1000 \mathrm{Al}$ particles included on the cross section to ensure that the polydisperse suspension calculated in the 1-D simulation is physically reasonable. The calculated 1-D detonation velocity is equal to $D=1560 \mathrm{~m} / \mathrm{s}$, whereas the peak pressure is equal to $p_{\max } / p_{0}=26.85$. Compared with the results of monodisperse detonation, the detonation velocity and peak pressure do not change much, even with a continuous particle size distribution, which is consistent with the conclusions drawn in Ref. [5] for various particle diameters. The 1-D detonation structures of gas phase for the log-normal distribution at $t=2 \mathrm{~ms}$ are shown in Fig. 10, with the coordinate $x$ originating at the detonation front. The results of monodisperse detonation are repeated here for comparison. One important characteristic shown in Figs. 10a-10d is that most features of monodisperse $\mathrm{Al}$ detonation (including the double peaks in gas pressure, density, velocity profiles; and the kink in gas temperature profile) disappear for polydisperse detonation with this log-normal particle size distribution. There are only single peaks of gas quantities in the detonation front, and the changes of these quantities after shock compression become smooth, which is similar to the wave front structures in gaseous detonations.
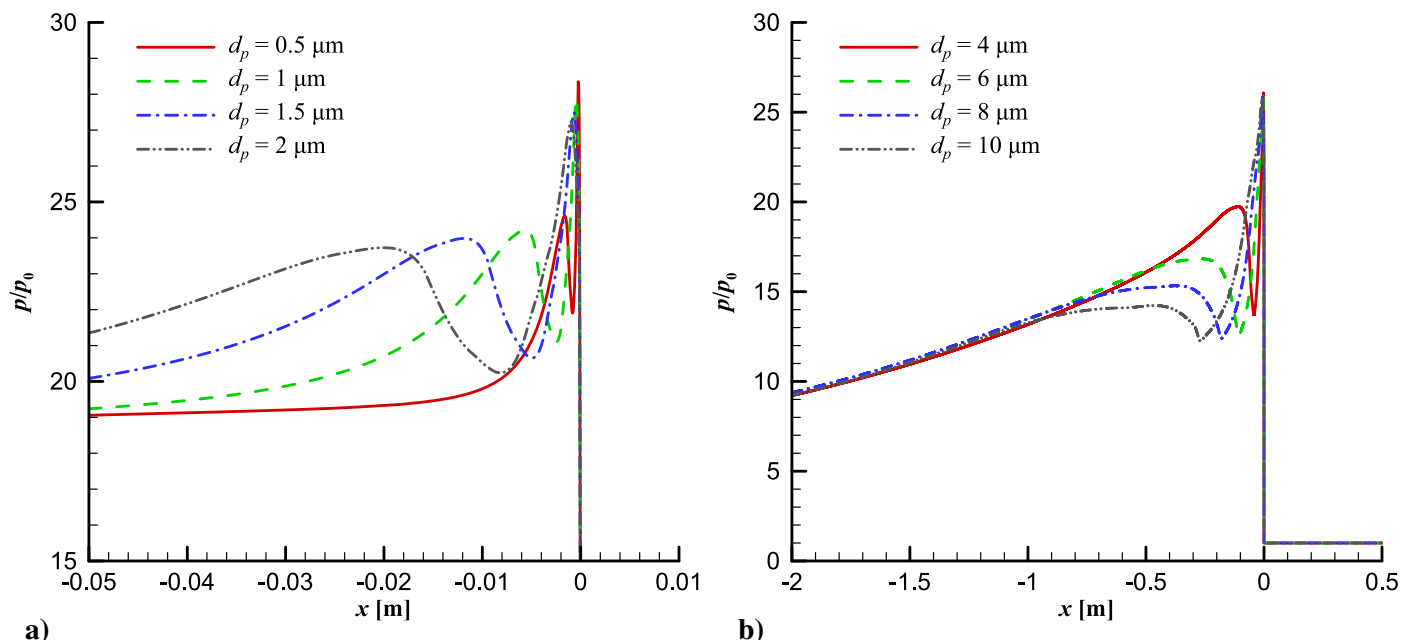

b)

Fig. 9 Pressure profiles of monodisperse Al-air detonation for different particle diameters: a) $0.5,1,1.5$, and $2 \mu \mathrm{m} ;$ and b) 4, 6, 8, and $10 \mu \mathrm{m}$. 


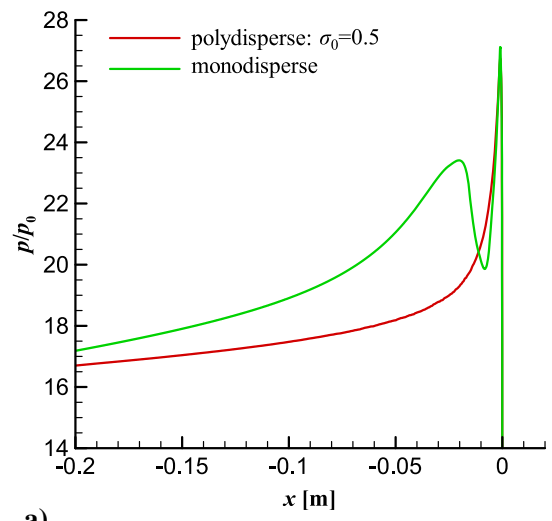

a)

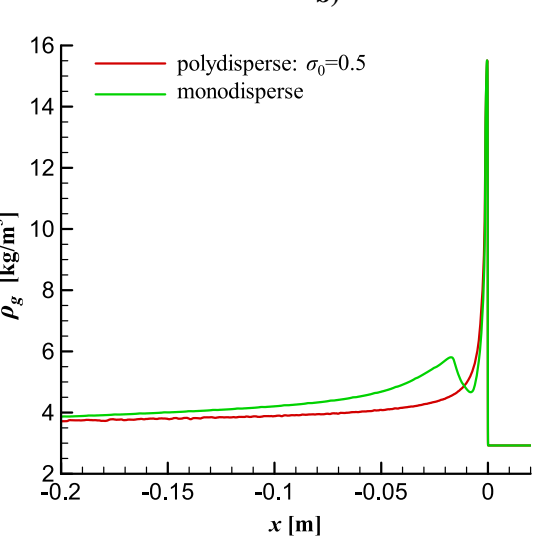

d)

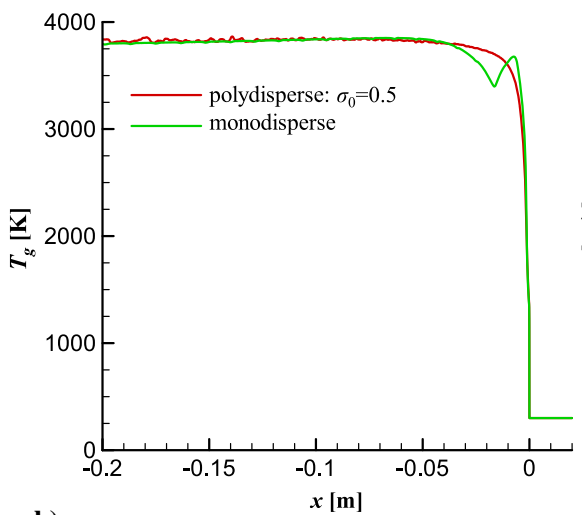

b)
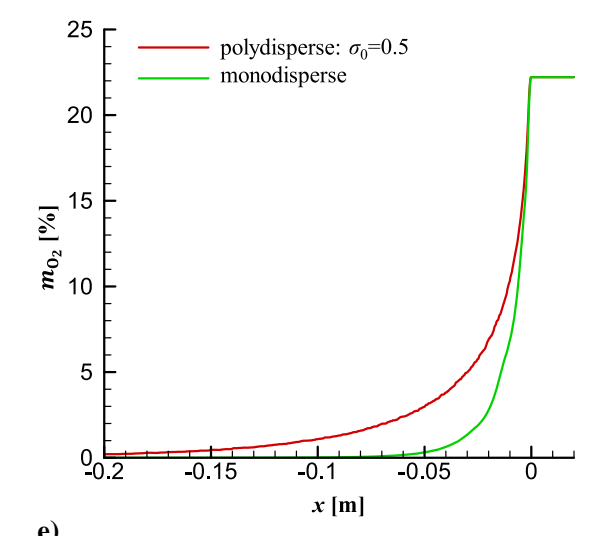

e)

Fig. 10 Comparison of front structures in gas phase of polydisperse and monodisperse Al-air detonations: a) pressure, b) temperature, c) velocity, d) density, and e) mass fraction of $\mathrm{O}_{2}$.

To explain the discrepancy between the monodisperse detonation and the polydisperse counterpart, the one-dimensional flow theory as described in Eqs. (28) and (29) is applied again. The results are shown in Fig. 11, and they reveal that the curve representing the total effect only has one zero point, which just divides the gas pressure variation into two stages. The increase of gas pressure just after shock compression is dominated by drag compression due to fast velocity relaxation in stage 1 , whereas the decrease of gas pressure before the $\mathrm{CJ}$ state is dominated by combustion of Al particles in stage 2 . The dominant heat transfer stage (stage 3 ) in monodisperse detonation does not exist anymore. Comparing the intensity of heat transfer here with that in the monodisperse detonation (Fig. 8), the intensity of heat transfer is more moderate throughout, is weaker than the momentum transfer in stage 1 , and is weaker than the combustion in stage 2, which explains the disappearance of stage 3 .

To further analyze the reasons for the formation of relatively more moderate heat transfer in the polydisperse detonation, the

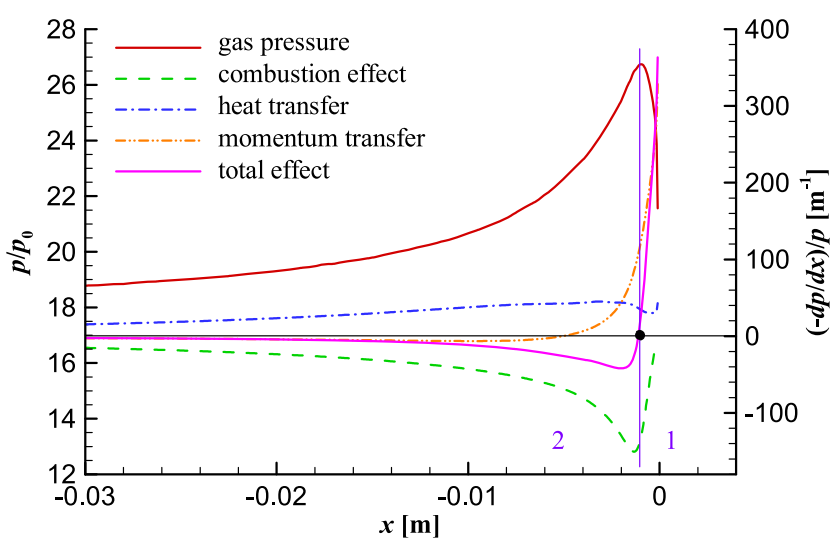

Fig. 11 Effects of combustion, heat transfer, and momentum transfer on gas pressure in polydisperse $\mathrm{Al}$-air detonation $\left(\sigma_{0}=0.5\right)$. temperature difference between gas and particles is analyzed. In the immediate neighborhood behind the shock, particles with different diameters are at different temperatures due to different heat transfer rates. Accordingly, an equivalent particle temperature $\bar{T}_{p}$ is introduced, based on the temperature difference calculated by the intensity of heat transfer:

$$
\left\{\begin{array}{l}
Q_{p}(x)=\sum_{d_{p}}\left\{K\left(x, d_{p}\right)\left[T(x)-T_{p}\left(x, d_{p}\right)\right]\right\} \\
\bar{T}_{p}(x)=T(x)-Q_{p}(x) / \sum_{d_{p}} K\left(x, d_{p}\right)
\end{array}\right.
$$

where $K\left(x, d_{p}\right)$ is the coefficient for calculating heat transfer between gas and particles with diameter of $d_{p}$. It is obvious that $\bar{T}_{p}$ is one kind of average particle temperature.

Figure 12 shows the transition process from monodisperse to polydisperse detonation by varying $\sigma_{0}$ from 0 to 0.5 with fixed $\bar{d}=2 \mu \mathrm{m}$. In Fig. 12a, with the increase of $\sigma_{0}$ in the log-normal distribution, the second peak in the pressure profile decreases gradually and disappears when $\sigma_{0}$ increases to about 0.3 . In Fig. $12 \mathrm{~b}$, the temperature plateau of $\mathrm{Al}$ evaporation in monodisperse detonation also gradually disappears in polydisperse detonations, which indicates that the evaporation of $\mathrm{Al}$ particles of different sizes occurs at different positions after the shock front in polydisperse detonation rather than intensely occurring at a specific location as in monodisperse detonation. As the heating rate of $\mathrm{Al}$ particle is proportional to $d^{-2}$, the time required to heat $\mathrm{Al}$ particles to the boiling point differs considerably in the polydisperse suspension, which results in the different evaporation positions for particles with different diameters. The same analysis can be applied to other phase transition processes. As discussed in Sec. III.B, phase transition is always accompanied by intense heat transfer. Thus, the space-dispersed phase transition processes of particles of different sizes in the polydisperse detonation result in the overall moderate heat transfer intensity. Moreover, with 

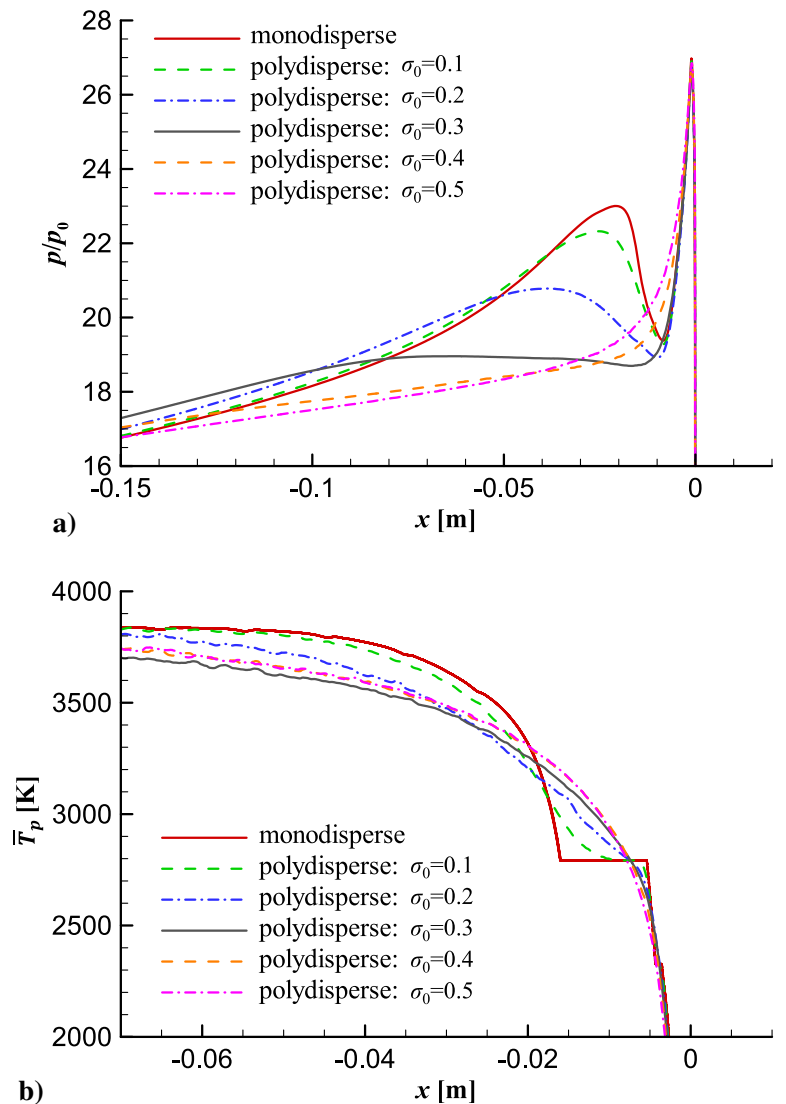

Fig. 12 Transition from monodisperse to polydisperse detonation by varying $\sigma_{0}$ from 0 to 0.5 : a) gas pressure, and b) equivalent particle temperature. a relatively wide particle size distribution, the phase transition processes (mainly $\mathrm{Al}$ evaporation) for particles of a certain diameter always occur at the combustion-dominant position for particles of another diameter. Also, when combustion is dominant, its intensity is always larger than that of heat transfer. Accordingly, the effect of combustion is always stronger than that of heat transfer for the polydisperse detonation with a relatively wide distribution, such as $\sigma_{0}>0.3$, which also results in the disappearance of the heattransfer-dominating stage. Evidently, these phenomena are attributed to the effects of multiple timescales and length scales in the polydisperse suspension with a continuous particle size distribution.

\section{2-D Heterogeneous Cellular Detonation}

In gaseous detonation, the cell size is greatly influenced by the characteristic length of reaction zone [44], which is also true for heterogeneous detonation. As shown in Fig. 10e, the reaction zone of the polydisperse detonation is larger than that of the monodisperse detonation, which will lead to different detonation cell sizes. The comparisons of the cellular detonations between the monodisperse $\mathrm{Al}$-air suspension with a uniform $2 \mu \mathrm{m}$ diameter and polydisperse Al-air suspensions with $\bar{d}=2 \mu \mathrm{m}$ and $\sigma_{0}=0.5$ and 0.8 are shown in Fig. 13 by peak pressure contours. Notably, a mesh size of $0.05 \mathrm{~mm}$ is used in all these 2-D cases with further convergence tests. The detonations are all directly initiated by the same small zones of high temperature and pressure at the left end of the computational domains, without any perturbance. As observed, the instability phenomenon occurs from about $x=0.15 \mathrm{~m}$ for the polydisperse detonations $\left(\sigma_{0}=0.5\right.$ and 0.8$)$ and from about $x=0.25 \mathrm{~m}$ for the monodisperse detonation. The detonation instability initiates earlier for the polydisperse detonations than the monodisperse counterpart. Last but not least, the estimated cell sizes of the monodisperse detonation and the polydisperse detonations $\left(\sigma_{0}=0.5\right.$ and $0.8)$ are $\lambda_{\text {monodisperse }}=10.5 \pm 0.5 \mathrm{~mm}, \lambda_{0.5}=13.3 \pm 0.8 \mathrm{~mm}$, and

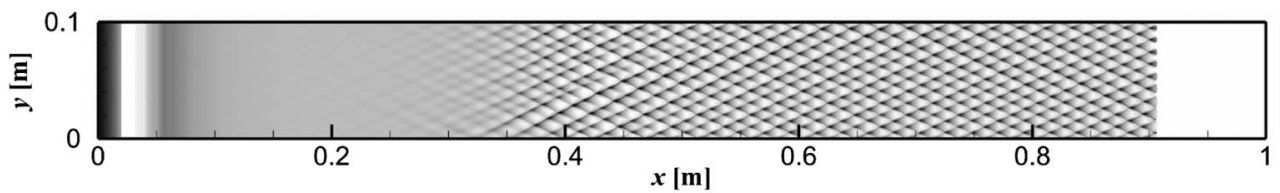

a) Monodisperse: $d_{p}=2 \mu \mathrm{m}, t=0.6 \mathrm{~ms}$

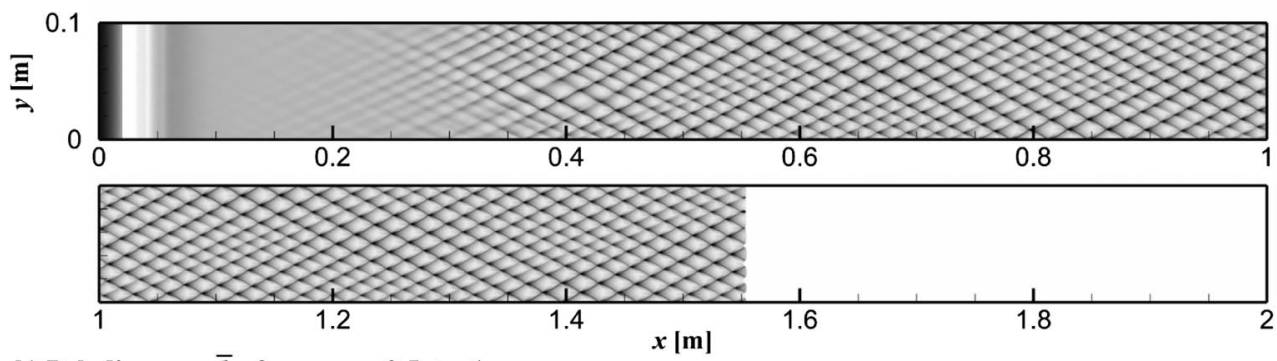

b) Polydisperse: $\bar{d}=2 \mu \mathrm{m}, \sigma_{0}=0.5, t=1 \mathrm{~ms}$
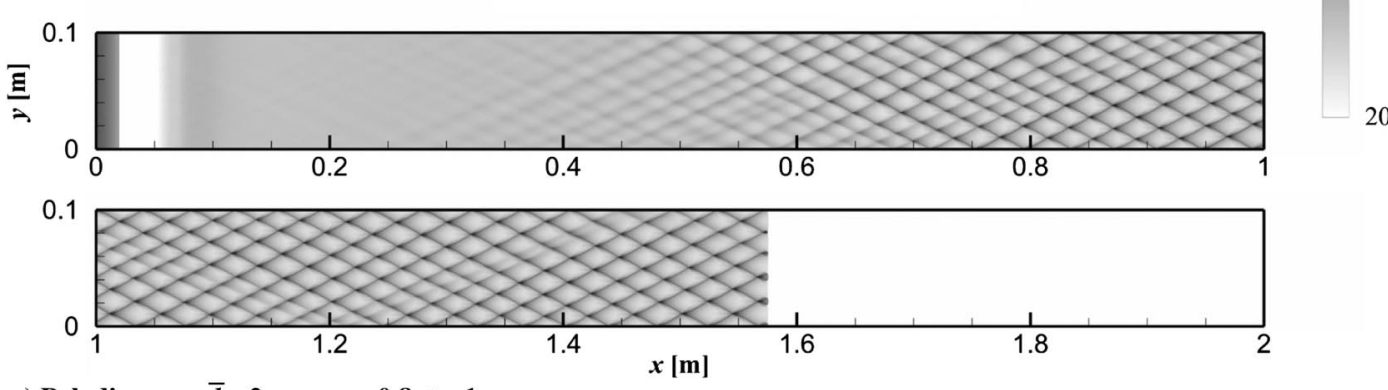

c) Polydisperse: $\bar{d}=2 \mu \mathrm{m}, \sigma_{0}=0.8, t=1 \mathrm{~ms}$

Fig. 13 Comparison of cellular detonations (peak pressure contours) of Al-air mixtures: a) monodisperse with $d_{p}=2 \mu \mathrm{m}$, b) polydisperse with $\bar{d}=2 \mu \mathrm{m}$ and $\sigma_{0}=0.5$, and c) polydisperse with $\bar{d}=2 \mu \mathrm{m}$ and $\sigma_{0}=0.8$. 


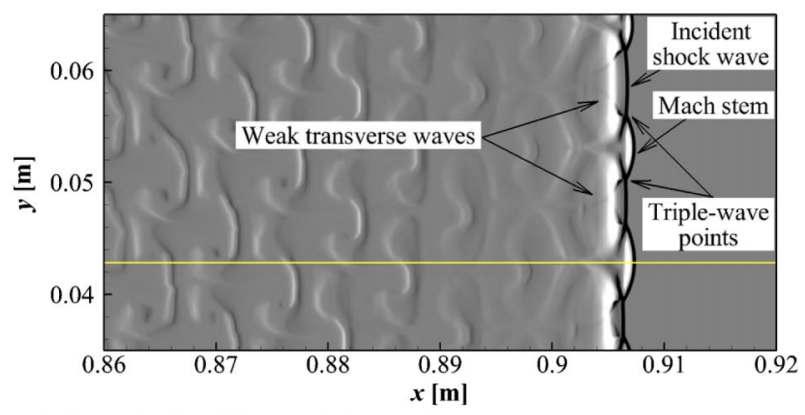

a) Numerical schlieren photographs

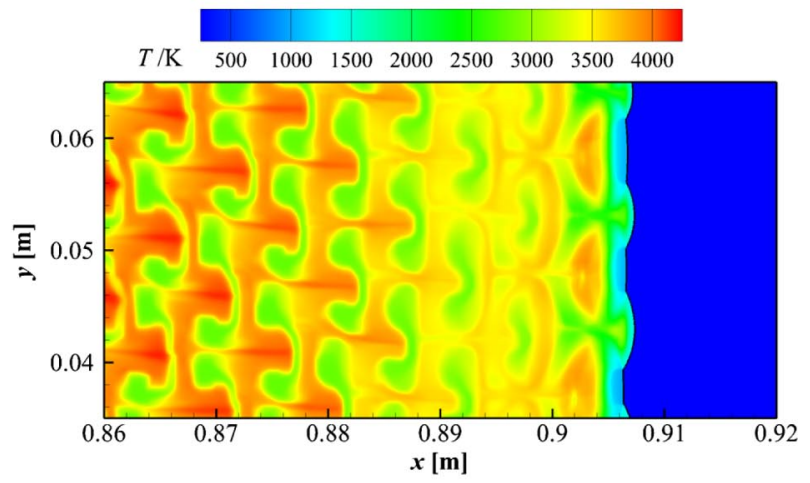

b) Gas temperature contours

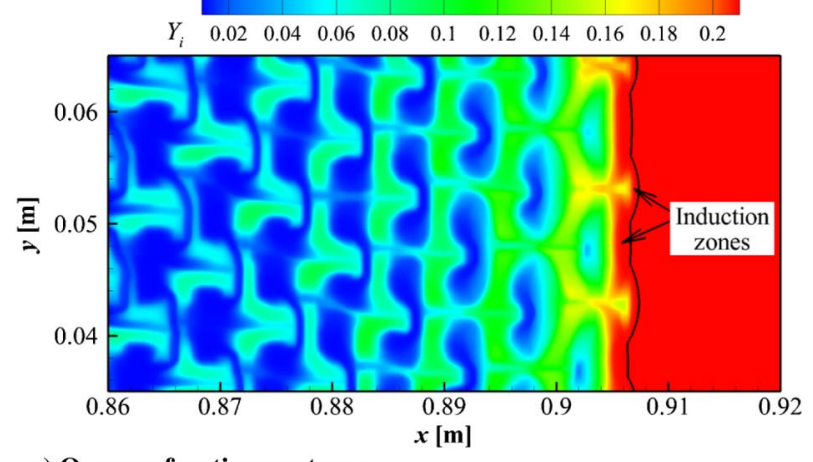

c) $\mathrm{O}_{2}$ mass fraction contours
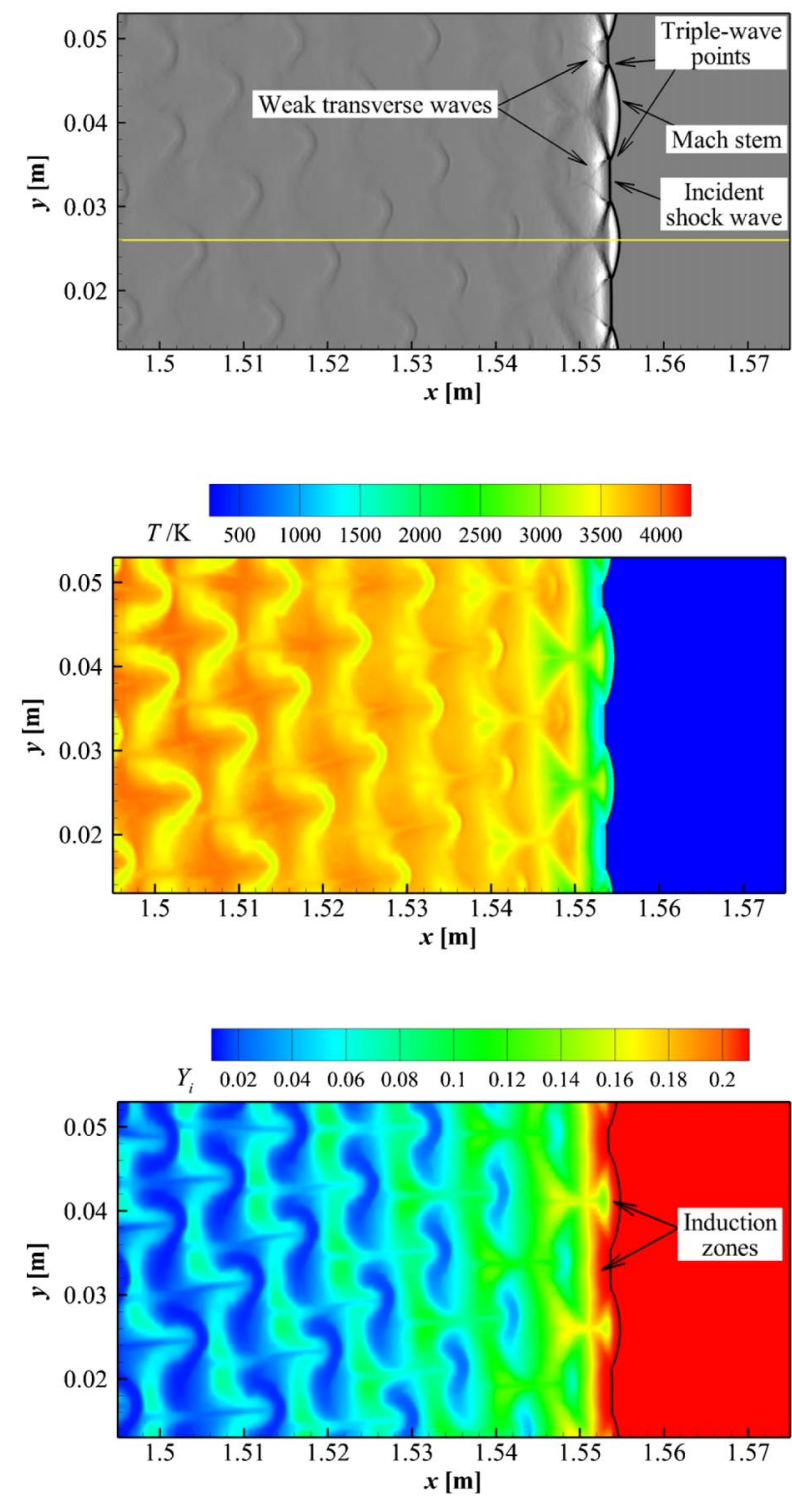

Fig. 14 Comparison of flowfields in Al-air detonation fronts: monodisperse with $d_{p}=2 \mu \mathrm{m}$ at $t=0.6 \mathrm{~ms}$ (left), and polydisperse with $\bar{d}=2 \mu \mathrm{m}$ and $\sigma_{0}=0.5$ at $t=1 \mathrm{~ms}$ (right).

$\lambda_{0.8}=20.0 \pm 1.8 \mathrm{~mm}$, respectively. Note that $\lambda_{0.5}$ is $27 \%$ larger than $\lambda_{\text {monodisperse }}$, and $\lambda_{0.8}$ is even $90 \%$ larger.

Notably, apart from the difference in detonation cell sizes, similarities between monodisperse and polydisperse detonations can be observed in cellular detonation flowfields. As indicated in Fig. 14a, both the monodisperse and polydisperse detonation fronts consist of pairs of triple points, Mach stems, incident shock waves, and pairs of transverse waves. Other similar features of cellular detonation flowfields between monodisperse and polydisperse detonations can also be observed in the temperature (Fig. 14b) and the $\mathrm{O}_{2}$ species mass fraction contours (Fig. 14c). The gas temperature and the $\mathrm{O}_{2}$ species mass fraction distributions for both monodisperse and polydisperse cases are nonuniform behind the detonation fronts, which are characterized by irregular local (high and low) temperature and $\mathrm{O}_{2}$ concentration zones, respectively. These irregular distributions of the flowfield parameters in monodisperse and polydisperse detonations are both caused by the periodical motions of triple points along the detonation fronts. Additionally, all these features in heterogeneous detonations are similar to those observed in purely gaseous detonations $[46,47]$, except for the transverse waves. The transverse waves in both the monodisperse and polydisperse detonation fronts are weak and degenerate fairly fast in the rear flows, which are different

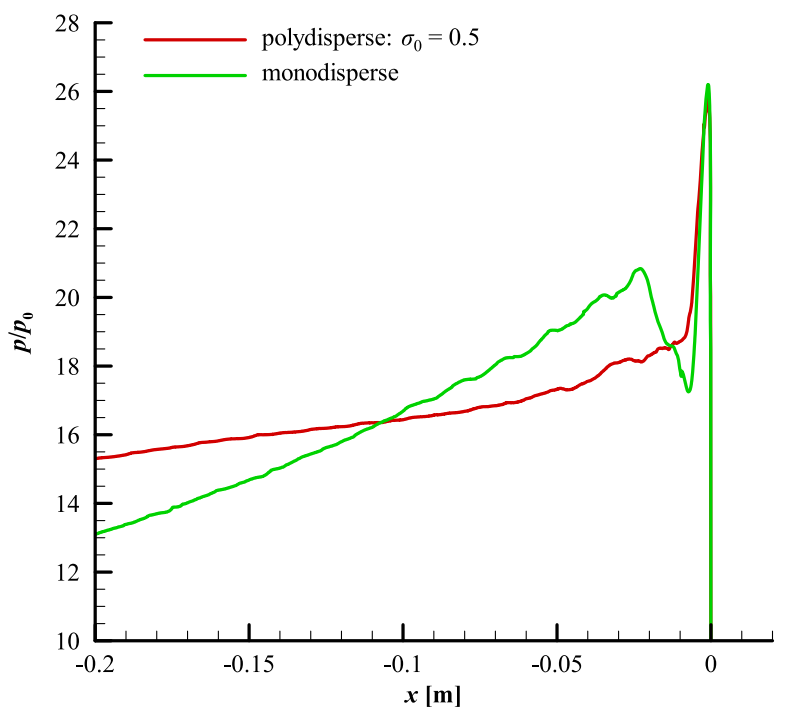

Fig. 15 Comparison of gas pressure distributions across Mach stems in 2-D monodisperse and polydisperse cellular detonations. 
from the strong transverse waves observed in purely gaseous detonations. According to Zhang and Gerrard [8], these weak transverse waves can be attributed to the slow diffusion-controlled combustion of the majority of $\mathrm{Al}$ particles after their kinetic inductions and a considerable amount of condensed Al oxide formed in the detonation products without contributing to gas pressure.

To further compare the difference between monodisperse and polydisperse detonations, gas pressure distributions across the Mach stems (along the blue lines shown in Fig. 14a) are extracted and shown in Fig. 15, with the coordinate $x$ originating from the detonation front. It can be revealed that the pressure profile is characterized by a single peak in the 2-D monodisperse cellular detonation and by double peaks in the 2-D polydisperse cellular detonation. This result implies that discrepancies in 1-D detonation front structures between monodisperse and polydisperse detonations can also be observed in 2-D cellular detonation front structures. The difference in the cell size, together with the difference in detonation front structures, indicates the great importance of considering particle size distribution in heterogeneous detonations.

\section{Conclusions}

In this study, the Al-air detonation is modeled in a computer code by the Eulerian-Lagrangian method along with the new hybrid Al combustion model, and the code has been verified by experiments. Using this code, the rich $2 \mu \mathrm{m} \mathrm{Al}$-air detonation in a polydisperse suspension with a log-normal particle size distribution was numerically studied, and the results were compared with those obtained in a monodisperse suspension consisting of only one particle size. It reveals that, in monodisperse $\mathrm{Al}$-air detonation, several two-phase detonation features (including the double peaks in gas pressure, density and velocity profiles, the particle temperature plateau, and thus the kink in gas temperature profile) could always be identified in the detonation front structures. However, in the polydisperse Al-air detonation $\left(\sigma_{0}=0.5\right)$, all these two-phase detonation features disappear, and the detonation front structures are very similar to those observed in gaseous detonation.

Quantitatively decoupling the gas-particles interactions by the one-dimensional flow theory, it is demonstrated that the double peaks feature in monodisperse detonation is caused by the dominant stage of heat transfer due to intense phase transition (Al evaporation) at a specific location after the shock front. In the polydisperse detonation, the space-dispersed phase transition processes of particles of different sizes result in an overall moderate heat transfer intensity, which hinders the formation of the heat-transfer-dominant stage; thus, the double peaks in the detonation front disappear. Moreover, the reaction zone of the polydisperse Al-air detonation is larger than that in the monodisperse detonation, which leads to the larger detonation cell size. The effects of multiple timescales and length scales in the polydisperse suspension with a continuous particle size distribution can be attributed to the different detonation structures between the monodisperse detonation and the polydisperse detonation. This study illustrates the significance of considering particle size distribution in heterogeneous detonation simulations and using the EulerianLagrangian method to track every particle individually.

\section{Acknowledgments}

This work was supported by the National Natural Science Foundation of China (grant nos. 11672312, 11772284, and 11532014); the Research Grants Council, Hong Kong (grant no. 152151/16E); the Department of Mechanical Engineering of the Hong Kong Polytechnic University (grant no. G-YBYJ); and the opening project of the State Key Laboratory of Explosion Science and Technology of the Beijing Institute of Technology (grant no. KFJJ18-12M).

\section{References}

[1] Abbasi, T., and Abbasi, S. A., "Dust Explosions-Cases, Causes, Consequences, and Control," Journal of Hazardous Materials, Vol. 140, Nos. 1-2, 2007, pp. 7-44. https://doi.org/10.1016/j.jhazmat.2006.11.007
[2] Myers, T. J., "Reducing Aluminum Dust Explosion Hazards: Case Study of Dust Inerting in an Aluminum Buffing Operation," Journal of Hazardous Materials, Vol. 159, No. 1, 2008, pp. 72-80. https://doi.org/10.1016/j.jhazmat.2008.02.106

[3] Tulis, A. J., and Selman, J. R., "Detonation Tube Studies of Aluminum Particles Dispersed in Air," Symposium (International) on Combustion, Vol. 19, No. 1, 1982, pp. 655-663.

https://doi.org/10.1016/S0082-0784(82)80240-3

[4] Zhang, F., Grönig, H., and Van de Ven, A., "DDT and Detonation Waves in Dust-Air Mixtures," Shock Waves, Vol. 11, No. 1, 2001, pp. 53-71. https://doi.org/10.1007/PL00004060

[5] Zhang, F., "Detonation of Gas-Particle Flow," Shock Wave Science and Technology Reference Library, Vol. 4, Springer, Berlin, 2009, pp. 87-168.

[6] Veyssiere, B., and Khasainov, B. A., "A Model for Steady, Plane, Double-Front Detonations (DFD) in Gaseous Explosive Mixtures with Aluminum Particles in Suspension," Combustion and Flame, Vol. 85, Nos. 1-2, 1991, pp. 241-253. https://doi.org/10.1016/0010-2180(91)90191-D

[7] Medvedev, A. E., Fedorov, A. V., and Fomin, V. M., "Description of Ignition and Combustion of Gas Mixtures with Solid Particles by Methods of the Mechanics of Continuous Media," Combustion, Explosion and Shock Waves, Vol. 20, No. 2, 1984, pp. 127-132. https://doi.org/10.1007/BF00751577

[8] Zhang, F., and Gerrard, K., "Reaction Mechanism of AluminumParticle-Air Detonation," Journal of Propulsion and Power, Vol. 25, No. 4, 2009, pp. 845-858. https://doi.org/10.2514/1.41707

[9] Papalexandris, M. V., "Numerical Simulation of Detonations in Mixtures of Gases and Solid Particles," Journal of Fluid Mechanics, Vol. 507, May 2004, pp. 95-142. https://doi.org/10.1017/S0022112004008894

[10] Papalexandris, M. V., "Influence of Inert Particles on the Propagation of Multidimensional Detonation Waves," Combustion and Flame, Vol. 141, No. 3, 2005, pp. 216-228. https://doi.org/10.1016/j.combustflame.2004.12.017

[11] Fedorov, A. V., and Khmel', T. A., "Numerical Simulation of Formation of Cellular Heterogeneous Detonation of Aluminum Particles in Oxygen," Combustion, Explosion and Shock Waves, Vol. 41, No. 4, 2005, pp. $435-448$. https://doi.org/10.1007/s10573-005-0054-7

[12] Briand, A., Veyssiere, B., and Khasainov, B. A., "Modelling of Detonation Cellular Structure in Aluminium Suspensions," Shock Waves, Vol. 20, No. 6, 2010, pp. 521-529. https://doi.org/10.1007/s00193-010-0288-5

[13] Veyssiere, B., Khasainov, B. A., and Briand, A., "Investigation of Detonation Initiation in Aluminium Suspensions," Shock Waves, Vol. 18, No. 4, 2008, pp. 307-315. https://doi.org/10.1007/s00193-008-0136-Z

[14] Teng, H. H., and Jiang, Z. L., "Numerical Simulation of OneDimensional Aluminum Particle-Air Detonation with Realistic Heat Capacities," Combustion and Flame, Vol. 160, No. 2, 2013, pp. 463-472. https://doi.org/10.1016/j.combustflame.2012.10.018

[15] Teng, H. H., and Jiang, Z. L., "Effects of Different Product Phases in Aluminum Dust Detonation Modeling," Science China Physics, Mechanics and Astronomy, Vol. 56, No. 11, 2013, pp. 2178-2185. https://doi.org/10.1007/s11433-013-5268-1

[16] Fedorov, A. V., and Khmel', T. A., "Structure and Initiation of Plane Detonation Waves in a Bidisperse Gas Suspension of Aluminum Particles," Combustion, Explosion and Shock Waves, Vol. 44, No. 2, 2008, pp. $163-171$. https://doi.org/10.1007/s10573-008-0022-0

[17] Fedorov, A. V., and Khmel', T. A., "Formation and Degeneration of Cellular Detonation in Bidisperse Gas Suspensions of Aluminum Particles," Combustion, Explosion and Shock Waves, Vol. 44, No. 3 , 2008, pp. 343-353. https://doi.org/10.1007/s10573-008-0042-9

[18] Durst, F., Milojevic, D., and Schönung, B., "Eulerian and Lagrangian Predictions of Particulate Two-Phase Flows: A Numerical Study," Applied Mathematical Modelling, Vol. 8, No. 2, 1984, pp. 101-115. https://doi.org/10.1016/0307-904X(84)90062-3

[19] Patankar, N. A., and Joseph, D. D., "Modeling and Numerical Simulation of Particulate Flows by the Eulerian-Lagrangian Approach," International Journal of Multiphase Flow, Vol. 27, No. 10, 2001, pp. $1659-1684$. https://doi.org/10.1016/S0301-9322(01)00021-0

[20] Crowe, C. T., Schwarzkopf, J. D., Sommerfeld, M., and Tsuji, Y., Multiphase Flows with Droplets and Particles, 2nd ed., CRC Press, Boca Raton, FL, 2012, pp. 39-56. 
[21] Olsen, S. E., and Becksteed, M. W., "Burn Time Measurements of Single Aluminum Particles in Steam and $\mathrm{CO}_{2}$ Mixtures," Journal of Propulsion and Power, Vol. 12, No. 4, 1996, pp. 662-671. https://doi.org/10.2514/3.24087

[22] McBride, B. J.,Zehe, M. J., and Gordon, S., "NASA Glenn Coefficients for Calculating Thermodynamic Properties of Individual Species," NASA TP-2002-211556, 2002.

[23] Bucher, P., Yetter, R. A., Dryer, F. L., Parr, T. P., and Hanson-Parr, D. M., "PLIF Species and Ratiometric Temperature Measurements of Aluminum Particle Combustion in $\mathrm{O}_{2}, \mathrm{CO}_{2}$, and $\mathrm{N}_{2} \mathrm{O}$ Oxidizers, and Comparison with Model Calculations," Symposium (International) on Combustion, Vol. 27, No. 2, 1998, pp. 2421-2429. https://doi.org/10.1016/S0082-0784(98)80094-5

[24] Liang, Y., and Beckstead, M. W., "Numerical Simulation of Quasi-Steady, Single Aluminum Particle Combustion in Air," AIAA Paper 1998-0254, 1998.

[25] Benkiewicz, K., and Hayashi, A. K., "Two-Dimensional Numerical Simulations of Multi-Headed Detonations in Oxygen-Aluminum Mixtures Using an Adaptive Mesh Refinement," Shock Waves, Vol. 12, No. 5, 2003, pp. 385-402. https://doi.org/10.1007/s00193-002-0169-7

[26] Benkiewicz, K., and Hayashi, A. K., "Parametric Studies of Aluminum Combustion Model for Simulations of Detonation Waves," AIAA Journal, Vol. 44, No. 3, 2006, pp. 608-619. https://doi.org/10.2514/1.20412

[27] Beckstead, M. W., "A Summary of Aluminum Combustion," Brigham Young Univ. Rept. RTO-EN-023, Provo, UT, 2002.

[28] King, M. K., "Modeling of Single Particle Aluminum Combustion in $\mathrm{CO}_{2}-\mathrm{N}_{2}$ Atmospheres" Symposium (International) on Combustion, Vol. 17, No. 1, 1979, pp. 1317-1328. https://doi.org/10.1016/S0082-0784(79)80124-1

[29] Friedman, R., and Maček, A., "Ignition and Combustion of Aluminium Particles in Hot Ambient Gases," Combustion and Flame, Vol. 6 , Jan. 1962, pp. 9-19. https://doi.org/10.1016/0010-2180(62)90062-7

[30] Zhang, F., Murray, S. B., and Gerrard, K. B., "Aluminum Particles-Air Detonation at Elevated Pressures," Shock Waves, Vol. 15, No. 5, 2006, pp. 313-324. https://doi.org/10.1007/s00193-006-0027-0

[31] Davis, A., "Solid Propellants: The Combustion of Particles of Metal Ingredients," Combustion and Flame, Vol. 7, Jan. 1963, pp. 227-234. https://doi.org/10.1016/0010-2180(63)90212-8

[32] Bazyn, T., Krier, H., and Glumac, N., "Oxidizer and Pressure Effects on the Combustion of 10-Micron Aluminum Particles," Journal of Propulsion and Power, Vol. 21, No. 4, 2005, pp. 577-582. https://doi.org/10.2514/1.12732

[33] Zhang, Z., Wen, C., Liu, Y., Zhang, D., and Jiang, Z., "Application of CE/SE Method to Gas-Particle Two-Phase Detonations Under an Eulerian-Lagrangian Framework," Journal of Computational Physics, Vol. 394, Oct. 2019, 18-40. https://doi.org/10.1016/j.jcp.2019.05.025

[34] Wang, G., Zhang, D. L., Liu, K. X., and Wang, J. T., "An Improved CE/SE Scheme for Numerical Simulation of Gaseous and TwoPhase Detonations," Computer and Fluids, Vol. 39, No. 1, 2010, pp. 168-177. https://doi.org/10.1016/i.compfluid.2009.07.010

[35] Chang, S. C., "The Method of Space-Time Conservation Element and Solution Element-A New Approach for Solving the Navier-Stokes and
Euler Equations," Journal of Computational Physics, Vol. 119, No. 2, 1995, pp. 295-324.

https://doi.org/10.1006/jcph.1995.1137

[36] Shen, H., and Parsani, M., "The Role of Multidimensional Instabilities in Direct Initiation of Gaseous Detonations in Free Space," Journal of Fluid Mechanics, Vol. 813, Feb. 2017, Paper R4. https://doi.org/10.1017/jfm.2017.5

[37] Shi, L. S., Shen, H., Zhang, P., Zhang, D. L., and Wen, C. Y., "Assessment of Vibrational Non-Equilibrium Effect on Detonation Cell Size," Combustion Science and Technology, Vol. 189, No. 5, 2017, pp. 841-853. https://doi.org/10.1080/00102202.2016.1260561

[38] Shen, H., Wen, C. Y., and Zhang, D. L., "A Characteristic Space-Time Conservation Element and Solution Element Method for Conservation Laws," Journal of Computational Physics, Vol. 288, May 2015, pp. 101-118. https://doi.org/10.1016/j.jcp.2015.02.018

[39] Shen, H., and Wen, C. Y., "A Characteristic Space-Time Conservation Element and Solution Element Method for Conservation Laws II. Multidimensional Extension," Journal of Computational Physics, Vol. 305, Jan. 2016, pp. 775-792. https://doi.org/10.1016/j.jcp.2015.11.017

[40] Shen, H., Wen, C. Y., Parsani, M., and Shu, C. W., "MaximumPrinciple-Satisfying Space-Time Conservation Element and Solution Element Scheme Applied to Compressible Multifluids," Journal of Computational Physics, Vol. 330, Feb. 2017, pp. 668-692. https://doi.org/10.1016/j.jcp.2016.10.036

[41] Ropp, D. L., and Shadid, J. N., "Stability of Operator Splitting Methods for Systems with Indefinite Operators: Advection-DiffusionReaction Systems," Journal of Computational Physics, Vol. 228, No. 9 , 2009, pp. 3508-3516. https://doi.org/10.1016/j.jcp.2009.02.001

[42] Saito, T., Marumoto, M., and Takayama, K., "Numerical Investigations of Shock Waves in Gas-Particle Mixtures," Shock Waves, Vol. 13, No. 4, 2003, pp. 299-322. https://doi.org/10.1007/s00193-003-0217-y

[43] Ingignoli, W., Veyssiere, B., and Khasainov, B. A., "Study of Detonation Initiation in Unconfined Aluminum Dust Clouds," Gaseous and Heterogeneous Detonations: Science to Applications, edited by G. D. Roy, S. M. Frolov, K. Kailasanath, and N. N. Smirnov, ENAS Publishers, Moscow, 1999, pp. 337-350.

[44] Gavrikov, A. I., Efimenko, A. A., and Dorofeev, S. B., "A Model for Detonation Cell Size Prediction from Chemical Kinetics," Combustion and Flame, Vol. 120, Nos. 1-2, 2000, pp. 19-33. https://doi.org/10.1016/S0010-2180(99)00076-0

[45] Anderson, J. D., Modern Compressible Flow with Historical Perspective, 2nd ed., McGraw-Hill, New York, 1990, pp. 45-99.

[46] Gamezo, V. N., Desbordes, D., and Oran, E. S., "Two-Dimensional Reactive Flow Dynamics in Cellular Detonation Waves," Shock Waves, Vol. 9, No. 1, 1999, pp. 11-17. https://doi.org/10.1007/s001930050134

[47] Gamezo, V. N., Desbordes, D., and Oran, E. S., "Formation and Evolution of Two-Dimensional Cellular Detonations," Combustion and Flame, Vol. 116, Nos. 1-2, 1999, pp. 154-165. https://doi.org/10.1016/S0010-2180(98)00031-5

D. S. Stewart Associate Editor 